\title{
La historia de la familia y la demografía histórica en la Europa rural, siglos XVI-XVIII. Evoluciones recientes, 2000-2019
}

\author{
Family history and historical demography in rural Europe, 16th-18th centuries. Recent bibliography developments, \\ 2000-2019 \\ Francisco García González \\ Universidad de Castilla-La Mancha, España \\ francisco.ggonzalez@uclm.es \\ Cosme Jesús Gómez Carrasco \\ Universidad de Murcia, España \\ cjgomez@um.es
}

\begin{abstract}
Resumen:
¿Qué lugar les corresponde en la actualidad a los estudios sobre la población y la familia en el marco de la historia rural europea de la época moderna? ¿Siguen siendo dos campos científicos interconectados? ¿Se trata de un tipo de conocimiento meramente acumulativo y continuista de unas líneas de investigación ya trazadas? ¿No hay margen para la innovación? El objetivo de este artículo es hacer un balance de lo realizado durante estas dos últimas décadas así como apuntar algunas propuestas de futuro. Se trata de un recorrido de la historia de las estructuras a la historia social de la población que, con un marcado carácter relacional y diferencial, está abriendo el camino hacia una renovación historiográfica que puede considerarse profunda e innovadora en algunos aspectos, al contrario de la imagen trasnochada y caduca que con frecuencia se ofrece de este ámbito de investigación.
\end{abstract}

Palabras clave: Historiografía, Historia de la Familia, Demografía Histórica, Historia social de la población, Historia rural.

\section{Abstract:}

What determined place have currently population and family studies among European rural history in Modern Age? Are they still being two inter-connected scientific fields? Is it just a continuist and accumulative type of knowledge about research areas that are already drawn up? Is there no room for innovation? The aim of this paper is to review the last two decades' work as well as concrete future proposals. A journey through population social history structures that, with a strong relational and differential character, is opening way to a historiographic renovation, which can be considered deep and innovative in certain aspects unlike the outdated and old-fashioned image that is frequently offered from this research field.

KEYworDs: Historiography, History of the Family, Historical Demography, Social History of Population, Rural History, Europe, Modern Age.

\section{INTRODUCCIÓN}

¿Qué ${ }^{1}$ lugar les corresponde en la actualidad a los estudios sobre la población y la familia en el marco de la historia rural europea de la época moderna? ¿Siguen siendo dos campos científicos interconectados? ¿Se trata de un tipo de conocimiento meramente acumulativo y continuista de unas líneas de investigación ya trazadas? ¿Las preguntas ya están hechas y las respuestas dadas? ¿Sólo se puede, en su caso, clarificar o matizar cuestiones que fueron abordadas hace tiempo? ¿No hay margen para la innovación? Estos son algunos de los interrogantes que nos planteamos en este artículo y que trataremos de resolver a partir del análisis de la producción historiográfica más reciente.

Dado el extraordinario desarrollo que tuvo la demografía histórica en paralelo al dinamismo que caracterizó a la historiografía ruralista europea antes de finales de los años 80, parece como si las muy abundantes monografías de antaño, repetidas persistentemente, hubiesen agotado la investigación de un

\section{Recepción: 19 Abril 2020 | Aceptación: 04 Junio 2020 | Publicación: 01 Abril 2021}


mundo como el rural en el que, sin embargo, vivía la mayor parte de la población. Porque Europa, como España, era ruralidad en la época moderna (Eiras Roel, 2004). Nuestro objetivo con este artículo es hacer un balance de lo realizado sobre la historia de la familia y la demografía histórica en la producción científica que podemos incluir dentro de la historia rural en la Europa moderna durante estas dos últimas décadas ${ }^{2}$. Se trata de un recorrido de la historia de las estructuras a la historia social de la población que, con un marcado carácter relacional y diferencial, está abriendo el camino hacia una renovación historiográfica que puede considerarse profunda e innovadora en algunos aspectos, al contrario de la imagen trasnochada y caduca que con frecuencia se ofrece de este ámbito de investigación (García González, 2014).

Para alcanzar nuestras pretensiones seguiremos dos procedimientos. Uno más general y otro más concreto. Primero nos centraremos en el análisis de las principales temáticas abordadas por los artículos publicados y registrados en un servicio en línea de información científica tan reconocido internacionalmente como Web of Science (WoS), referidos a los dominios de esta investigación. Será un análisis preocupado por observar no sólo el peso e importancia de los temas sino también sus conexiones y agrupaciones. En segundo lugar, examinamos los contenidos de las principales revistas europeas especializadas en historia rural y de estudios de la población o afines y analizaremos los trabajos que publicaron sobre demografía histórica e historia de la familia de la Edad Moderna en el período de estudio.

Con respecto al primer objetivo, se han descargado los metadatos de los artículos publicados entre 2000 y 2019 en Web of Science. A partir de ese universo se han aplicado diferentes criterios de búsqueda en la categoría "tema" de la herramienta de la WoS por medio de la web de la Fundación Española de Ciencia y Tecnología (FECYT). Se trata de una herramienta que permite realizar búsquedas de los temas objeto de investigación mediante los términos indicados en el título, en las palabras clave y en el resumen de los trabajos publicados. En este caso hemos realizado tres tipos de análisis: primero se buscaron los artículos que incluyeran el término "historical demography"; después aquellos en los que, además, junto a este término figurara el concepto "family"; y, por último, se hizo otra búsqueda con "rural history", "agrarian history" o "agricultural history".

Para el segundo objetivo se han analizado de forma detallada e individualizada los artículos en cuya cronología figuraran -en todo o en parte- los siglos XVI, XVII y XVIII, y que hubieran sido publicados entre el año 2000 y 2014 en revistas europeas especializadas, fundamentalmente, en historia rural y demografía histórica. Para ello se han seleccionado, en el primer caso, cinco publicaciones periódicas: Histoire et Societés Rurales; Études Rurales; Historia Agraria; Estudis d'Historia Agraria; y Rural History. Society, Economy and Culture. Y en segundo lugar tres: Annales de Demographie Historique, Revista de Demografía Histórica y Popolazione e Storia. Junto a ellas se han utilizado otras nueve revistas de historia, pero más generalistas, editadas en dos países, Francia y España, con larga tradición en investigación sobre historia rural. Entre las revistas galas se seleccionaron cuatro: Revue d'Histoire Moderne et Contemporaine; Histoire et Mesure; Revue Historique; e Histoire, Economie et Societé. Y entre las españolas cinco: Obradoiro de Historia Moderna; Studia Historica. Historia Moderna; Hispania; Historia Social; y Revista de Historia Económica. El criterio seguido para la selección de este tipo de publicaciones más generalistas fue que se tratara de revistas que aceptasen trabajos de historia social, económica o relacionada con la población y que, además, ocuparan posiciones importantes en bases de datos de prestigio como SCOPUS. En conjunto, se han consultado y vaciado 17 revistas con un total de 4033 artículos, de los que 383 se refieren al mundo rural; y de ellos, 132 al objeto de nuestra investigación (Cuadro 1 del Anexo).

\section{El marco general. Un aNÁlisis bibliográfico Previo}

El análisis de redes bibliométricas nos permitirá representar y observar la estructura conceptual de nuestros campos de estudio y ver si están interconectados. En este sentido, se han utilizado dos técnicas: la 
visualización de similitudes y el mapeo. La combinación de estos dos procedimientos posibilita obtener una representación más precisa y completa, global y progresiva del dominio temático ${ }^{3}$.

Como comentamos, a partir de la base de datos del Core Collection de Web of Science hemos realizado la búsqueda de trabajos académicos entre 2000 y 2019 en los que apareciera el término "historical demography", en el título, en el resumen o en las palabras clave. Los resultados obtenidos ( 860 artículos) ponen de manifiesto el predominio de temáticas ligadas a la biología o la paleontología, en gran medida relacionadas con la estructura genética o la biogeografía. Mientras, los aspectos sociales o vinculados a la población eran muy secundarios y desvirtuaban el análisis que pretendíamos realizar. Ante esta circunstancia, acotamos todavía más nuestra búsqueda. Junto al término "historical demography" añadimos el de "family", objeto de nuestro estudio. Los resultados encontrados se redujeron notablemente: sólo 92 artículos de los 860 mencionados. Sin embargo, consideramos que, a modo de indicadores, son un buen exponente de los intereses actuales que atraen la atención de los investigadores dentro del dominio que vincula demografía histórica y familia. Como se comprueba en el Gráfico 1, en el que se recogen los 20 términos más frecuentes utilizados en las publicaciones, sin lugar a dudas los campos que más sobresalen son los que versan sobre mortalidad (agregando la general con la infantil), la suma del matrimonio y la fertilidad, y todo lo relativo a la población, su evolución y crecimiento. A continuación, figurarían la emigración y otras variables que pueden aglutinarse en torno a los intentos de modelizar patrones de comportamiento y sus factores determinantes. Finalmente, si bien su presencia es menor, es significativo el interés por cuestiones como la edad o los hogares y su composición. Asimismo, es llamativo que, con respecto al espacio, se mencione a Europa y, desde el punto de vista temporal, el siglo XIX.

Gráfico 1. Términos más frecuentes en los artículos sobre demografía histórica y familia en WoS (2000-2019)

\section{Most Relevant Words}

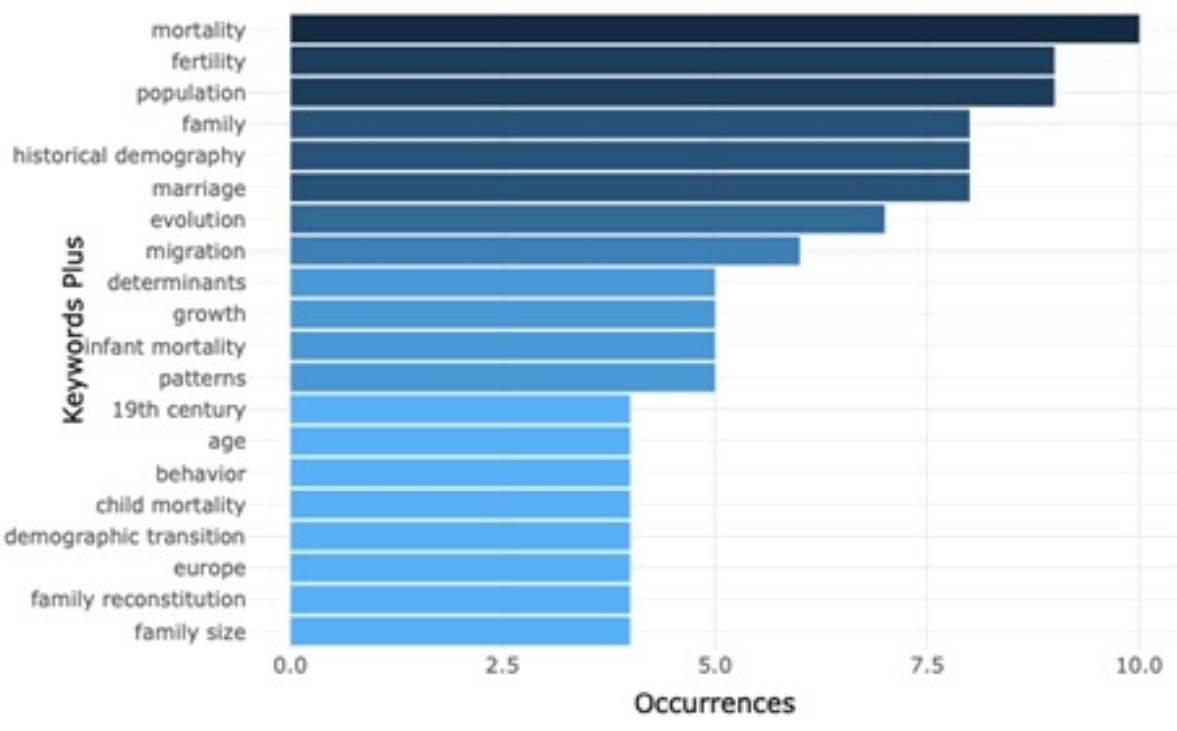

Fuente: Web of Science

Grosso modo, la red de co-ocurrencias de las palabras clave utilizadas por los autores nos confirma la imagen obtenida. La Figura 1 del Anexo nos muestra esta red en cuatro clústeres. El primero (color rojo) agrupa fundamentalmente las temáticas demográficas más relacionadas con la mortalidad, la salud, la edad y la longevidad. El segundo (color verde) interrelaciona sobre todo las variables más ligadas a la familia, el matrimonio, la fertilidad o el parentesco. El tercer clúster (azul), por su parte, con menos componentes, incide en el hogar en diferentes territorios y épocas. Mientras, el cuarto clúster (amarillo) concentra el concepto 
fuerza de demografía histórica, sus métodos y modelos, así como su derivación más biológica, genética y biogeográfica.

Siguiendo con esta misma metodología, tratamos de ver cuál era la imagen que nos ofrece la historia rural como campo de investigación. Para ello establecimos como criterios de búsqueda en la base de datos del Core Collection de Web of Science los artículos que tuvieran las palabras "rural history", "agricultural history" o "agrarian history". El resultado fueron 631 documentos entre 2000 y 2019. Como se puede comprobar en el Gráfico 2, en realidad, por encima de todo, este ámbito científico se identifica de forma abrumadora con la historia de la agricultura o, en su caso, con la historia agraria, y no tanto con el concepto "rural". Priman, en consecuencia, las perspectivas de tipo económico. Junto a la agricultura, se destacan los trabajos sobre la tierra y su uso, seguidos de los aspectos ecológicos y medioambientales. No encontramos en las 20 primeras palabras utilizadas como descriptores términos de búsqueda que nos relacionen la historia rural o agraria con la historia de la familia (matrimonio, herencia, parentesco, explotaciones familiares, etc.) o con cuestiones demográficas y de población. Es una conexión que tampoco percibimos cuando la exploración la hacemos desde el otro lado, desde el ámbito de la demografía histórica o de la historia de la familia, como hemos visto antes. Con lo cual, si para afrontar los retos de futuro la demografía histórica no debe aislarse de otras ramas de la investigación histórica (Saito, 1997, p. 169), en el caso de la historia rural existe una dificultad manifiesta.

Gráfico 2. Términos más frecuentes en los artículos sobre historia rural en WoS (2000-2014)

\section{Most Relevant Words}

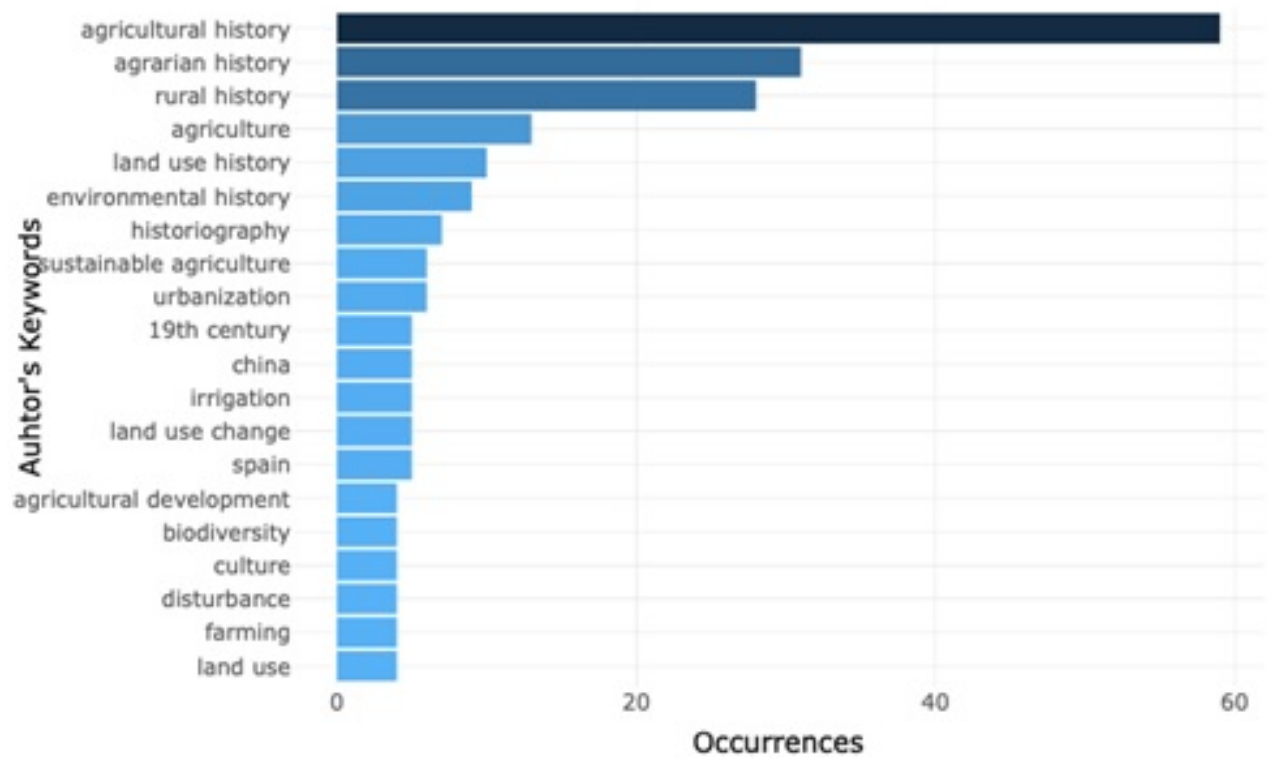

Fuente: Web of Science

Para comprobar la forma en que estaban interrelacionadas estas palabras claves procedimos a crear otra red de co-ocurrencias. En la Figura 2 del Anexo podemos ver las agrupaciones obtenidas. La primera gira en torno al nodo "agricultural history" (color verde). En este clúster se conectan temáticas de tipo económico (agricultura, tierra, economía, crecimiento, gestión, sistemas de producción) o socioeconómico ("farmers”, mujeres, desigualdad). Ligado a este clúster y a las temáticas más sociales hay otro más secundario (color azul), en torno a las palabras "rural history" y "agrarian history", en el que resalta el término "historiografía", lo que denota el interés teórico y metodológico que suscitan estos campos, en especial en España, que brilla con luz propia. Porque sería injusto considerar que la historia agraria no ha evolucionado y se ha quedado completamente estancada. Sobre todo, en relación con la perspectiva sostenible, tanto desde el punto de vista ambiental como social, así como en los análisis institucionales (González de Molina, 2012; Iriarte Goñi, 2013). 
No es extraño, pues, que el segundo de los grandes clústeres configure una red mucho más tupida en torno a cuestiones con un componente claramente ecológico, como los términos utilizados demuestran: "vegetación”, “diversidad”, “conservación”, "paisaje”, "bosques”, etc. Este clúster se imbrica a su vez con otra agrupación muy secundaria (color amarillo), que refuerza el perfil anterior al ligar temas parecidos, como cambios en el uso de la tierra. Y aquí aparece sólo -y de manera periférica- un término como "migración", que podemos enlazar con el ámbito demográfico. Con lo cual, una vez más comprobamos la escasa conexión de la historia rural con la demografía histórica o la historia de la familia.

\section{LA DEMOgRAFíA HISTÓRICA Y LA HISTORIA DE LA FAMILIA EN EL MUNDO RURAL DE LA EUROPA MODERNA}

El dinamismo de la investigación tanto en historia rural como en demografía histórica e historia de la familia se refleja con nitidez en las actividades desarrolladas por las asociaciones nacionales de dichas especialidades. Pero, además, la intensidad del movimiento asociativo se ha traducido, en el caso de Europa, en el surgimiento de la European Rural History Organisation (EURHO) y de la European Society of Historical Demography (ESHD). Conseguir una mayor colaboración entre los investigadores y su vertebración a nivel internacional es un logro sin precedentes que demuestra la gran trascendencia de estas dos décadas iniciales del siglo XXI para el impulso de estas disciplinas científicas. Sin embargo, es curioso que las confluencias existentes con anterioridad entre dichas disciplinas ahora se hayan diluido. El distanciamiento es manifiesto, a tenor del contenido de sus congresos. ${ }^{4}$

Centrándonos en el caso concreto del período moderno, comprobamos cómo la economía en general y la historia rural en particular son en la actualidad temáticas poco frecuentadas por los historiadores; nada que ver con lo que ocurría antes de los años 90, cuando ambas eran privilegiadas por la investigación. Sin embargo, en otras especialidades esto no sucede y estos temas cuentan con un enorme desarrollo. El ejemplo de España y de Portugal es paradigmático. En la Sociedad Española de Historia Agraria (SEHA) o en la Rede de História Rural em Portuguès (Rural RePort) que forma parte de la Sociedade Portuguesa de Estudos Rurais (SPER), los historiadores académicamente adscriptos al área de conocimiento de historia moderna son muy minoritarios en comparación con los de la época contemporánea, los historiadores económicos, los sociólogos o los pertenecientes a otras ciencias sociales ${ }^{5}$. Y lo mismo ocurre en la Asociación de Demografía Histórica $(\mathrm{ADEH})$, que aglutina a especialistas hispanos y portugueses. La importante representación del modernismo historiográfico entre los socios se ha reducido drásticamente, así como las publicaciones al respecto (Dubert, 2015a). Todas ellas son ejemplos de asociaciones constituidas con profesionales procedentes de distintas disciplinas e instituciones, cuyo objetivo es impulsar los estudios sobre la población y el mundo rural en el pasado y en el presente. Es un esfuerzo compartido del que, curiosamente, se han ido separando los historiadores modernistas. Quizá la mejor evidencia es su escasa participación en los sucesivos congresos que vienen organizando estas asociaciones. Mientras que el número de congresistas y de sesiones paralelas propuestas no deja de crecer, su presencia no deja de descender. Y más cuando nos referimos a las temáticas relacionadas con la demografía histórica ${ }^{6}$.

Es evidente que quedan muy lejos los tiempos en los que la historia rural y la demografía histórica iban de la mano en el proceso de renovación historiográfica impulsado por autores como Eiras Roel en España o Pierre Goubert en Francia. En este país, y a partir de sus conocidas tesis ruralistas, se fue configurando desde los años 60 un modelo agrodemográfico de investigación que daría como resultado la proliferación de investigaciones con una fuerte base regional o comarcal. Eran monografías que vinculaban el estudio de la población y el poblamiento con sus bases económicas como punto de partida para analizar la organización social.

Paulatinamente, frente a los registros parroquiales y al método de reconstrucción de familias sobre el que se sustentaban aquellas monografías, se fueron imponiendo las propuestas del Grupo de Cambridge a partir 
de la explotación de los padrones de población y el tamaño, la estructura y la composición de los hogares. En este tránsito salió perdiendo la atención a la población rural, como ocurrió en el caso de España en opinión de Rey Castelao (2016). Se trata de un ejemplo paradigmático, por cuanto la consolidación de la historia de la familia como línea de investigación desde mediados de los años 80 coincidió con el progresivo declive del tipo de monografías ruralistas “a la francesa” (García González, 2007, 2015).

\subsection{Radiografía de un dominio científico. La demografía histórica en el campo}

De acuerdo con las revistas analizadas (Cuadro 1 del Anexo), se constata que las investigaciones sobre el mundo rural en la Edad Moderna son escasas: ni siquiera llegan a la décima parte del conjunto de los artículos publicados (9,5\%). Como es lógico, entre las revistas especializadas en historia rural las proporciones son muy diferentes. Sobresalen Histoire et Societés Rurales y Estudis d'Historia Agraria al multiplicar por cuatro el promedio general, con el 38,1 y el 36,6 por ciento de sus artículos, respectivamente. Entre una quinta y una sexta parte de los textos los encontramos en Rural History Journal (21,1 \%) y en Historia Agraria (15,9 \%). Con un carácter contemporáneo muy claro figuraría Études Rurales $(2,4 \%)$. Del lado de las revistas dedicadas al estudio de la población en el pasado, los resultados no son tampoco muy halageños: 16,9 \% en la Revista de Demografía Histórica, 13,9 en Popolazione e Storia y 13,6 en Annales de Demographie Historique. Del resto de revistas históricas analizadas sobresale Obradoiro de Historia Moderna (16,7 \%) porque en Studia Historica. Historia Moderna (7,2 \%) y en Historie et Mesure (5,9\%) la presencia del mundo rural de la época moderna es aún menor. Y en el resto de las revistas analizadas es anecdótica pues ni siquiera llega al 3 o $4 \%$ de los artículos publicados. El dinamismo de la investigación que reflejan las actividades desarrolladas por las asociaciones nacionales e internacionales de historia rural o de demografía histórica no se corresponde para la Edad Moderna con la producción publicada en estos campos. Y no parece que la tendencia vaya a cambiar, a tenor de la evolución anual que observamos en las revistas en estos primeros años del siglo XXI.

El interés de la investigación en historia rural tiene un perfil eminentemente contemporáneo. El peso que tienen los economistas y los sociólogos es evidente, pero también se observa una apuesta por parte de los propios historiadores para adentrarse de lleno en la segunda mitad del siglo XX (Iriarte Goñi, 2013, p. 9). En nuestro caso, acotando como universo de análisis sólo los artículos referidos a la historia de la familia o la demografía histórica en la Edad Moderna, constatamos (Gráficos 3 y 4 ) una clara tendencia a que los estudios abarquen toda la centuria ilustrada o parte de ella, encabalgada con el siglo XIX, es decir, que se interesen por el período de transición hacia la época contemporánea. Es un dato que contrasta con el número muy bajo de los artículos que se adentran en el periodo de transición de la Edad Media a la Edad Moderna. Mucho menor, incluso, que los planteados en lo que hemos denominado larga duración, es decir, los trabajos que engloban varios siglos más allá de la época moderna, bien por iniciarse a finales del medievo o bien por llegar hasta el siglo XX. 
Gráfico 3. Cronologías: períodos analizados en los artículos sobre historia de la familia y demografía histórica del mundo rural de la Edad Moderna (2000-2014)

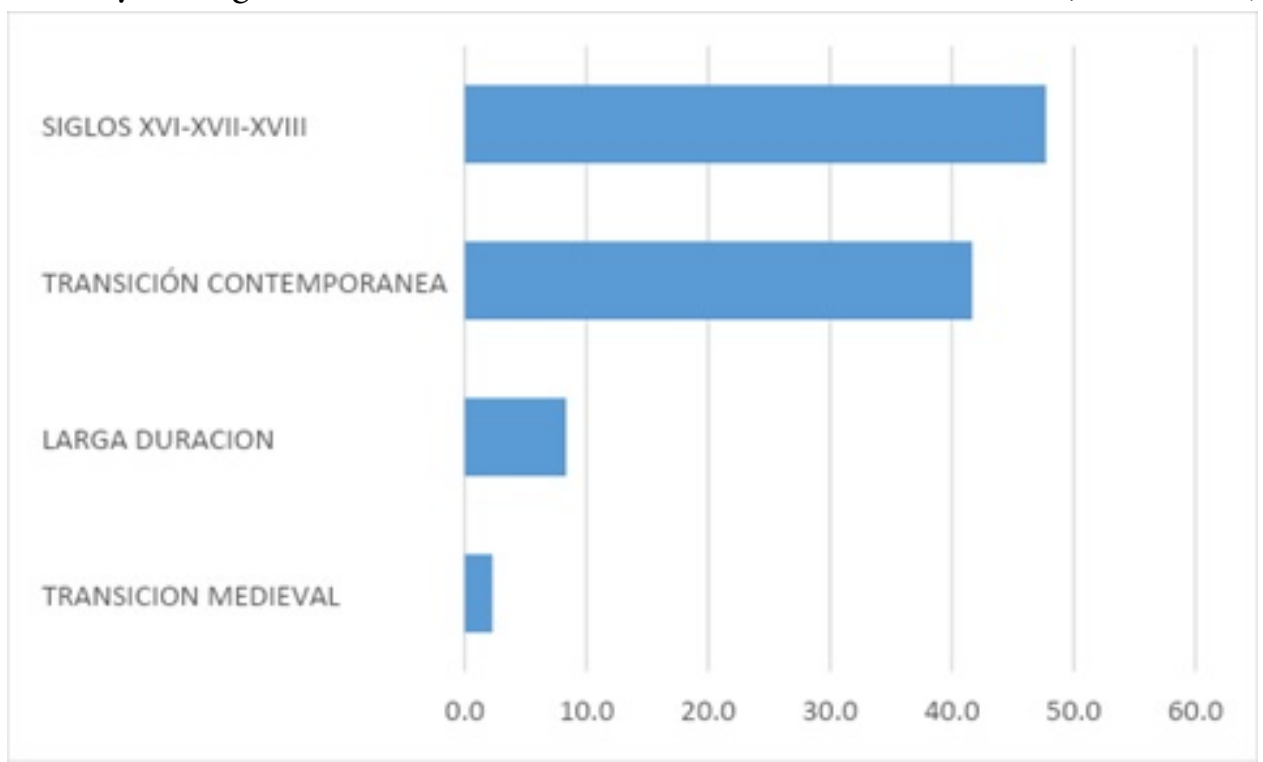

Fuente: Anexo Cuadro 1 Nota: “Transición contemporánea” se refiere a los trabajos situados a caballo entre los siglos XVIII y XIX; “Transición medieval” a los situados entre los siglos XV y XVI; "Larga duración”, a los engloban varios siglos más allá de la Edad Moderna, bien por iniciarse a finales de la Edad Media o bien por llegar hasta el siglo XX.

Dado el carácter de la muestra, como es obvio sobresalen los artículos que analizan exclusivamente algún período incluido dentro del arco temporal de la época moderna, pero no todos los siglos han recibido la misma atención de los investigadores. De una manera aplastante sobresale el siglo XVIII, con casi el $42 \%$ de las referencias.

Gráfico 4. Cronología secular en los artículos sobre historia de la familia y demografía histórica del mundo rural de la Edad Moderna (2000-2014)

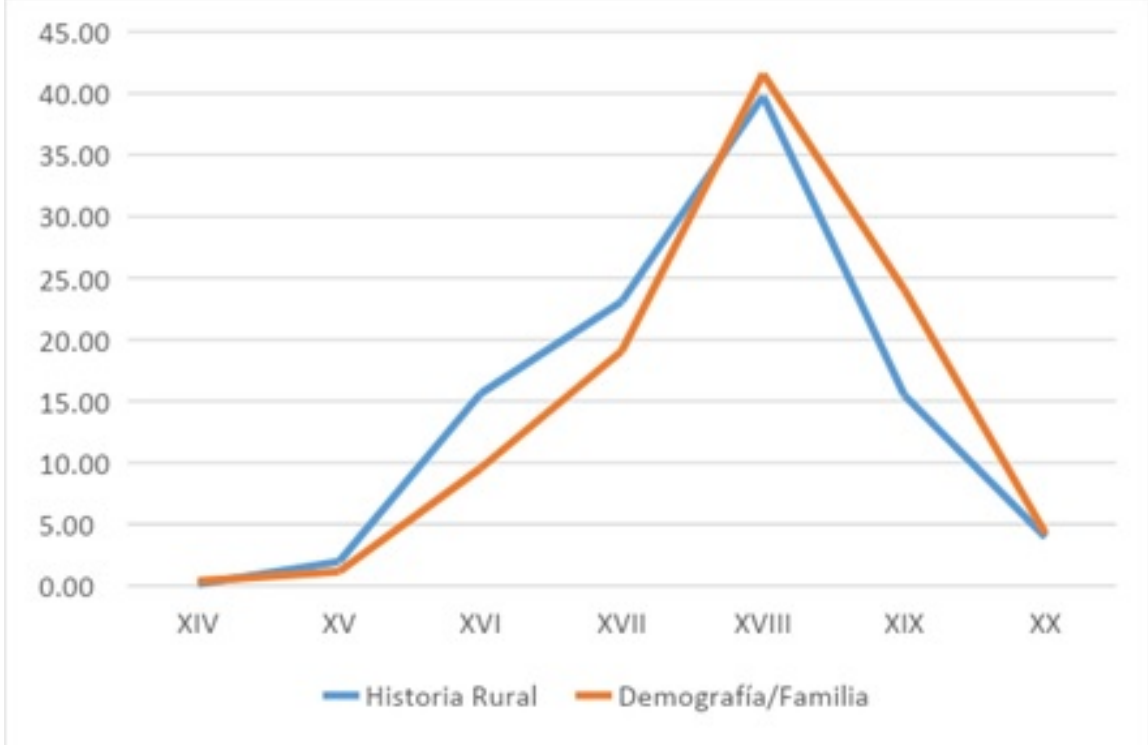

Fuente: Anexo cuadro 1

Por lo que respecta al análisis temático (Gráfico 5), se confirma de forma nítida que predominan los temas vinculados a la historia agraria y con un claro perfil económico. Son temas como los cultivos y la producción; 
la tierra, su propiedad, distribución y tenencia; la ganadería y la pesca; los aspectos técnicos y de innovación; el paisaje y cuestiones del medio ambiente; el mercado, el consumo y los niveles de vida. En segundo lugar, constatamos que los temas que podemos incluir dentro de la historia de la familia y de la demografía histórica supondrían alrededor de una tercera parte del total (34,5\%). A continuación, están las publicaciones que abordan aspectos relacionados con las instituciones y la fiscalidad (Estado, Iglesia, comunidad, señoríos, legislación, normas, costumbres y propuestas de reforma). En contraste con el peso que tienen las variables con un sesgo económico figura la atención prestada a los grupos sociales y a la conflictividad, muestra palpable de la necesidad de hacer más hincapié en una perspectiva más social en el futuro. Se trata de una carencia que debe ir acompañada, estamos convencidos, de una mayor reflexión teórica y metodológica; un campo que, sin ser abandonado, no está entre las prioridades de los investigadores, como corrobora el gráfico ${ }^{7}$.

Gráfico 5. El mundo rural de la Edad Moderna en las revistas europeas. Una aproximación temática, 2000-2014

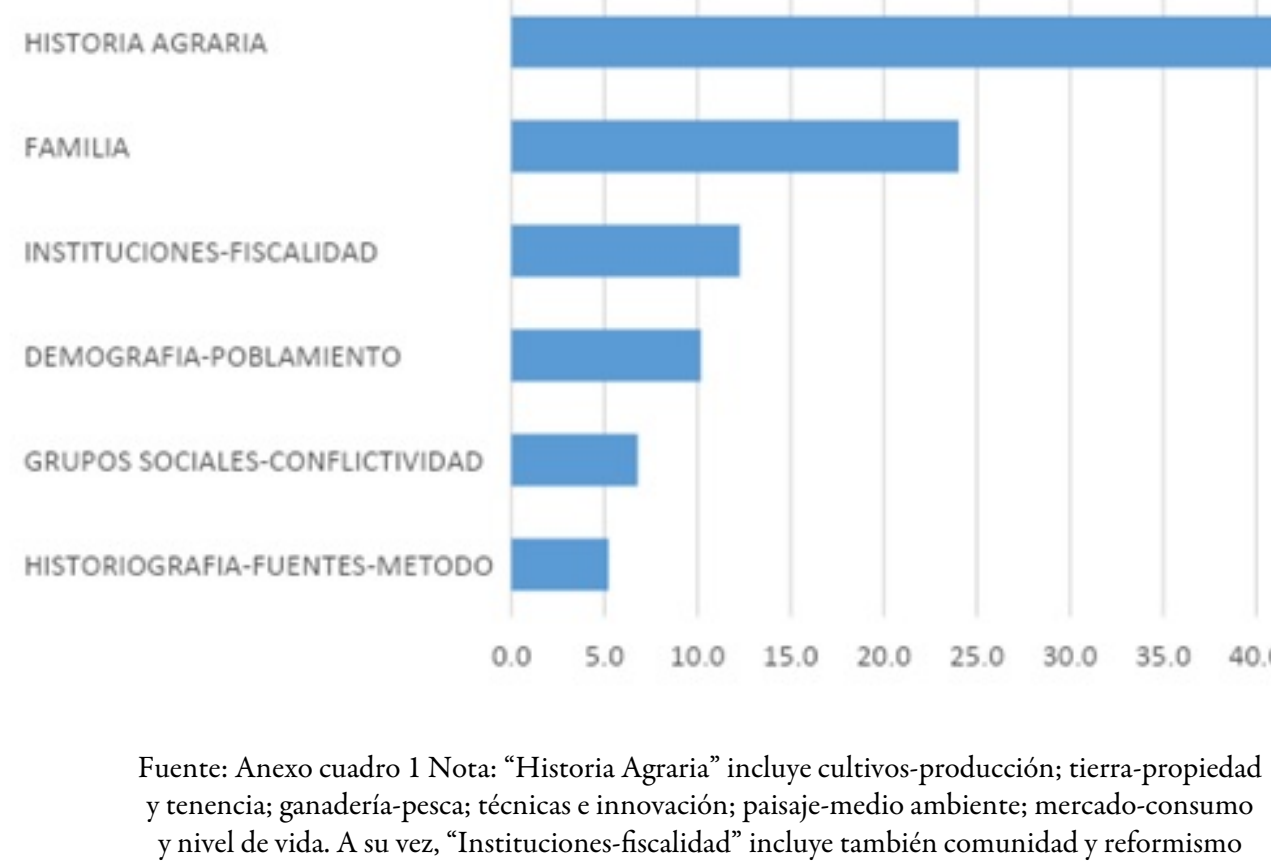

Fijándonos sólo en los artículos sobre el mundo rural en la época moderna, la presencia de la historia de la familia y de la demografía histórica no es igual en todas las revistas. Al margen de la Revista de Demografía Histórica, Annales de Demographie Historique o Popolazione e Storia, cuyo perfil especializado justifica estas temáticas, de nuevo comprobamos que en las revistas específicas de historia rural su proporción es baja. En Estudis d'Historia Agraria un 20 \% y en Histoire et Societés Rurales, 16,4.Desde luego, ello no se corresponde con el peso de la edad moderna en el conjunto de los artículos de contenido rural publicados en estas revistas (36,6 y 38,1 \%, respectivamente). Y menor presencia tienen aún dichos artículos en Rural History Journal (15,8\%) o en Historia Agraria (11,6\%). Por el contrario, más de la mitad de los textos sobre el mundo rural de Obradoiro de Historia Moderna se refieren a estas temáticas, muestra del interés que aún continúa en Santiago de Compostela por las investigaciones que ligan la población y el mundo rural. La escasa representatividad de lo rural en el resto de las revistas impide obtener conclusiones significativas salvo que, prácticamente en todas ellas, se trata de temas vinculados a la historia de la familia y no a la demografía histórica. Se confirma una vez más, también, que el interés por la historia rural de la época moderna está muy alejado de los tradicionales aspectos que configuraron el modelo agrodemográfico de investigación que durante décadas primó entre los investigadores. 
En efecto, hay una clara desigualdad entre la atención prestada a los temas relacionados con la historia de la familia y a los más propios de la demografía histórica. La proporción, según nuestros cálculos, sería de 7 a 3; es decir, de cada diez trabajos sobre cuestiones de población y sociedad del mundo rural en la edad moderna, siete se encuadrarían dentro de la historia de la familia. Aquellos estudios, por ejemplo, que analizaban la evolución de la población y la producción agraria o los precios están del todo abandonados. Sí encontramos todavía algunos trabajos sobre las variables demográficas como la nupcialidad y la fecundidad o la estructura e intensidad de la mortalidad. Utilizando las metodologías e indicadores propios del microanálisis demográfico (Ardit, 1999; Breschi, Derosas y Viazzo, 2003), hay estudios que profundizan en los comportamientos reproductivos de las poblaciones rurales del Antiguo Régimen o en la larga duración, para comprender la transición demográfica ${ }^{8}$. Términos como "debilidad", "recesión", "resurgimiento", "recuperación", "euforia", "crecimiento" o "dinamismo demográfico" son el eje de varios artículos recogidos en la base de datos sobre la que fundamentamos esta investigación (Pérez García, 2009; Zeller, 2007; Dubert, 2002; Llopis Agelán et al., 2012; Paping, y Collenteur, 2004). Algunos otros nos hablan de concepciones prenupciales, matrimonios adolescentes o matrimonios tardíos (Buon, 2008; Palm y Schott, 2001), modelos socioeconómicos y de ocupación del espacio (Pérez Álvarez, 2005; Birgy, 2014; Castellani, 2010; Fornasin y Zannini, 2002), las coyunturas de crisis y la vulnerabilidad de las poblaciones (Alfani, 2010; Rao, 2009; Mikelarena y Erdozáin, 2002); o revisan y matizan las cronologías demográficas y agrarias establecidas hasta el momento (Ferrer i Alós, 2007; Vicedo, 2007).

Pero, entre los estudios demográficos, se destaca un tema por encima de los demás: las migraciones y la movilidad de la población (Rey Castelao, 2016; Minvielle, 2016). En nuestra base de datos, es significativo que más de una cuarta parte de los artículos se ocupe de él. Las nuevas generaciones de investigadores se han sumado con fuerza al largo debate (Dupâquier, 2002) que cuestionaba el estereotipo de unas comunidades totalmente sedentarias, endogámicas, viviendo casi de forma autárquica y cerradas al exterior. Y los planteamientos actuales son muy diferentes: las poblaciones rurales eran móviles (Rosental, 1999) aunque es cierto que hay zonas y regiones más propensas a la movilidad que otras-, sus desplazamientos no se producían únicamente del campo a la ciudad y en absoluto los campesinos estaban atados a la tierra (Croix, 1999; Boudjaaba, 2008). De todos modos, junto a las migraciones mejor conocidas, como las del campo a la ciudad o la movilidad del servicio doméstico, se han hecho esfuerzos por profundizar en los movimientos laborales y estacionales, especialmente en zonas con tradiciones migratorias consolidadas como las regiones montañosas (Fontaine, 2005; Blanco Carrasco, 2012a), o como los casos de los desplazamientos de gallegos y portugueses, entre otros, a Andalucía (Florencia y López Martínez, 2000; Infante, 2011), o de franceses hacia Cataluña y España en general (Salas, 1999; Capdevila, 2004). Incluso, las perspectivas se han invertido para fijarse en extranjeros que llegaban también a territorios de neta emigración, como Galicia (Salas, 2004). Aunque, cuando nos referimos a los extranjeros, más que en los campesinos en la historiografía suele primar la atención sobre comerciantes y agentes de negocios y de la administración (Villar y Pezzi, 2003).

Puesto que la movilidad era un proceso social, y que existían redes multipolares organizadas alrededor de diferentes puntos nodales, se están asumiendo unos planteamientos mucho más complejos que superan la tradicional mirada unidireccional campo-ciudad. Como hemos visto, se está insistiendo en los movimientos intra-rurales. Otros estudios imprimen una cierta mirada genealógica para seguir las huellas del movimiento (Brunet et al., 2008; Jordá, Vallas y Pujadas, 2013). Y sobre todo, cada vez más se insiste en el protagonismo de las mujeres (Rey Castelao, 2008), constreñidas hasta ahora en el clásico discurso del servicio doméstico hacia las ciudades. Incluso, se resalta su presencia hacia América porque, aunque eran mayoritarios, no sólo se fueron los hombres: también hubo mujeres (Poska, 2016).

Vamos conociendo cómo se fueron practicando migraciones en cadena a lo largo del tiempo sobre la base de las relaciones de parentesco y paisanaje. Pero un reto sobre el que hay que avanzar es el de la socialización e integración de los migrantes. ¿Hasta qué punto la distancia espacial suponía una ruptura familiar, social o, incluso, de identidad? Sabemos aún muy poco al respecto para el mundo rural, pero en algunas zonas 
como el País Vasco este tipo de cuestiones ha preocupado a sus historiadores. Por ejemplo, los trabajos de Alberto Angulo Morales (2015) indagan en cómo, en paralelo a los procesos migratorios de jóvenes provincianos norteños a ciudades como Madrid o a las colonias, iban surgiendo centros de ayuda al emigrante (hospitales, cofradías o congregaciones) por criterios de origen o naturaleza. Una especie de "comunidades emocionales", como las denomina el propio autor, que se convirtieron en verdaderas agencias de colocación, en espacios de representación cultural y política y en intermediarios entre los emigrantes y las autoridades de sus lugares de origen. Y como Madrid o Cádiz, hacia Londres se desplazaban también irlandeses y escoceses (Clark, 2000). Eran, en muchos casos, vidas transatlánticas, generalmente protagonizadas por campesinos procedentes de zonas rurales pero que, sin embargo, han interesado mucho menos que los comerciantes, militares, eclesiásticos, personal político y de la administración, servidores de la Corona y otros componentes de las élites y los grupos de poder. Entre otras causas porque la documentación personal en forma de correspondencia, memorias o diarios con la que se aborda cada vez más este tipo de temas es mucho más difícil de encontrar para quienes procedían del campo. Lo que no quita que, en un mundo transatlántico, transpacífico e interconectado, los esfuerzos se estén multiplicando para rastrear la vida de los africanos y sus descendientes, el destino de los moriscos o de los asiáticos que llegaron a las colonias (Garofalo, 2017; Cook, 2016; Seijas, 2014).

Cuando hablamos de migraciones, los análisis se plantean casi siempre en función de los que emigraron y no de quienes se quedaron. Efectivamente, hay que la importancia del parentesco, la vecindad, la amistad, el paisanaje y otro tipo de redes de ayuda y solidaridad en el lugar de destino de quien parte. Pero se suele olvidar lo que ocurre con quienes se quedan y el papel que juegan esos mismos vínculos u otros no tan altruistas, como los de clientela y patronazgo que refuerzan la dependencia. Como veremos más adelante, por este u otros motivos, los hogares solitarios o encabezados por un solo miembro de la pareja tuvieron una significativa presencia en las sociedades rurales del pasado.

Por otro lado, poner el énfasis en las migraciones ha relegado a un segundo plano la atención a las micromovilidades. Y cuando se ha hecho, el tema lo ha monopolizado casi por completo el tándem endogamia/ exogamia matrimonial y sus mayores o menores niveles según las zonas y localidades (Hayhoe, 2011). Mientras, cuando hablamos de movilidades "invisibles", no sólo nos referimos a las mujeres. Hubo otros grupos de edad distintos de los jóvenes y de los adultos que también se movían, como los ancianos. Eran movimientos ligados a la pobreza y la mendicidad, pero también a los cuidados, como por ejemplo la costumbre de rotar entre los hijos la asistencia familiar aunque los progenitores vivieran en poblaciones distintas.

Por desgracia, a pesar de los esfuerzos realizados, el mundo rural de la edad moderna queda aún lejos de las prioridades de la historiografía sobre la movilidad porque la atención sigue centrándose en la ciudad, sobre todo a partir del siglo XIX. Varias publicaciones recientes lo ponen de manifiesto (Dubert y Gourdon, 2017), así como los números monográficos dedicados al tema por revistas como Quaderni Storici (2001), Annales de Démographie Historique (2002) o la Revista de Demografía Histórica (2002).

\subsection{La familia y la historia social de la población en el mundo rural}

Como comentamos, durante estas dos últimas décadas los trabajos sobre historia de la familia se han multiplicado en comparación con los de demografía histórica estrictamente. Detrás de este conjunto de publicaciones se vislumbra un modelo de investigación que podemos aglutinar bajo el objetivo común de estudiar los procesos de reproducción y movilidad social. El modelo parte del matrimonio, contemplado más como fenómeno social que como acontecimiento demográfico, y de las estrategias diseñadas a partir de aquél, de tal modo que la alianza, el patrimonio y la herencia, como su vehículo de transmisión, constituyen los pilares fundamentales. 
Por lo general, se trata de estudios de caso referidos a una familia, a comunidades locales o a pequeñas comarcas. Las ventajas para el historiador de este tipo de monografías de reducida escala y con metodologías próximas a la microhistoria son evidentes para la comprensión de los mecanismos de organización y reproducción social en el pasado. Al modo del antropólogo, en ellas

es más fácil la aprehensión de una estructura social y jerarquizada, y más accesible la comprensión de las relaciones de poder y de las prácticas y discursos que lo legitiman y lo reproducen. Asimismo en su seno es especialmente factible la reconstrucción de las estrategias que dan sentido al conjunto de las prácticas sociales de individuos y colectivos, y la verificación de los conflictos resultantes de la puesta en práctica de dichas estrategias, a menudo, antagónicas en sus objetivos finales (Moreno y Palenzuela, 2000).

Sin duda, las cuestiones planteadas desde la antropología han permitido complejizar más la investigación de los historiadores de la familia (Bourdelais y Gourdon, 2000; Viazzo, 2007).

Con mucha menor intensidad que en la década de los 90, los estudios sobre el hogar que aplican la metodología de Peter Laslett siguen realizándose, aunque no tanto con el objetivo de confirmar o no la geografía de los modelos familiares establecidos por aquél sino como unidades relacionales y organizativas, claves en la lucha por la supervivencia y la reproducción. Además, se está insistiendo en análisis de tipo diferencial. Y no tanto para la comparación de regiones como para la de grupos sociales, grupos de edad o sexo de los cabezas de familia y los componentes de esta. Sin embargo, si se han multiplicado los trabajos aplicando criterios diferenciales socialmente, suelen realizarse a partir de las categorías socio-profesionales mientras que aún sabemos muy poco de las contrastes en función de la propiedad y tenencia de la tierra u otros bienes y medios de producción (García González, 2011). Se trata de un tema sobre el que conviene profundizar en el futuro.

Junto al estudio de las unidades familiares se han ido desarrollando también las investigaciones sobre la casa. Pero de la casa como hecho social (Hernández López, 2013; Birriel, 2017), superada ya esa mirada etnográfica que tendía a reducir el interés del historiador a la mera descripción constructiva o a la relación de enseres, ajuares y utensilios en la línea de describir usos y costumbres. Su entronque con nuevas propuestas sobre la esfera doméstica (Eibach y Lanzinger, 2020), el consumo o los procesos de civilización (García Fernández, 2017), la convierten en una cuestión de un enorme potencial.

A partir de la muestra de artículos que sirven de base a nuestro análisis, contemplando la producción historiográfica sobre historia de la familia en estos veinte años comprobamos cómo matrimonio, patrimonio, estrategia, herencia, transmisión, movilidad o reproducción social son los términos que con más insistencia se repiten en las publicaciones. Es decir, se pone el acento sobre los lazos más allá del hogar y no tanto en tratar de comprobar en qué medida el caso investigado se ajustaba a las supuestas interacciones entre las estructuras de los agregados domésticos, los sistemas de alianza y las costumbres de herencia propios de los modelos familiares ya establecidos (García González, 2007, pp.120-121; Dubert, 2005). Sistemas familiares, además, en los que se ha enfatizado la división entre los países del norte y el sur de Europa occidental, mientras que Europa del este se ha dejado fuera (Viazzo, 2009).

La importancia de los aspectos normativos y jurídicos (Viret, 2008) es clara pero la flexibilidad de los comportamientos trasciende el derecho. Independientemente del sistema de herencia, se insiste en las estrategias de transmisión, perpetuación y movilidad social (Béaur, 2017; Ferrer i Alós, 2011; Chacón, 2009) ${ }^{9}$. En este punto, por un lado, se resalta la tensión entre normas y prácticas pero también entre los deseos familiares y la decisión de los actores sociales ${ }^{10}$; por otro, la tierra ya no es el único objetivo de los investigadores sino cualquier tipo de bien (material o inmaterial); y finalmente, en contra de la simplicidad interpretativa que predominaba a la hora de estudiar los sistemas de herencia -sobre todo el de la transmisión igualitaria-, se están poniendo de manifiesto mecanismos que evidencian una gran complejidad. Entre otros, se evidencia una revalorización del papel del mercado en la circulación de bienes y la conformación de las explotaciones: compraventas, cesiones, arrendamientos y otras fórmulas dentro de un mercado intervenido por las redes de parentesco (Boudjaaba, 2005). 
En efecto, el parentesco y, en un sentido más extenso, la parentela (Tullio yy Lorenzini, 2014), es otro de los grandes temas de investigación que se están desarrollando con notable vitalidad. El estudio de la consanguinidad, no tanto en su vertiente biodemográfica ${ }^{11}$ como en la social, está volviendo a despertar con fuerza la atención de los investigadores ${ }^{12}$ después de poner de manifiesto su relevancia entre los historiadores, con autores como Raúl Merzario (1981). El estudio de los matrimonios consanguíneos y el reencadenamiento de alianzas está beneficiándose de las ventajas que proporciona la informática, pues permite acumular una masa muy considerable de datos de archivo y constituir un corpus genealógico de gran amplitud. En este sentido, otro de los grandes avances se está produciendo con respecto al parentesco espiritual y el padrinazgo (Alfani y Gourdon, 2012; Alfani et al., 2018; Quemener, 2018; Skorepová, 2018; García González y Gómez Carrasco, 2008), tras el impulso alcanzado a partir de la constitución de la red Patrinus liderada por Guido Alfani y Vincent Gourdon

En esa apuesta por profundizar en el complejo mundo de las relaciones sociales se están aplicando métodos de investigación más intensivos como el análisis de redes, genealogías y trayectorias, que nos permiten la observación directa de las relaciones interpersonales, las posibilidades de elección de los individuos y los procesos de movilidad social. Aunque, como veremos, se ha hecho más hincapié en las trayectorias de promoción que en las de descenso social, fundamentalmente estudiando la proyección de las familias hacia las instituciones civiles y eclesiásticas que les proporcionaban poder y estatus.

A través de la historia de la familia se está avanzado hacia el objetivo de elaborar una historia rural más social, no tanto en clave sólo de las estructuras como también en la de los actores para comprender y explicar los mecanismos de diferenciación y de desigualdad (García González, 2016; Boudjaaba, 2016), base, en definitiva, de las relaciones de dependencia, patronazgo y clientela. Esta línea de investigación se ha confirmado como una excelente vía para el estudio de las relaciones sociales en el campo, un proceso que es dinámico frente a los planteamientos tradicionales que suponen la cosificación de los grupos y categorías sociales como si fueran algo cerrado y estático (Congost, 2014). Si el objetivo es estudiar las dinámicas sociales y la reproducción diferenciada de la jerarquía y de la desigualdad, es imprescindible asumir una perspectiva de investigación también socialmente diferencial, algo que supone cuestionar la aplicación universal de conceptos como estrategia para, en cambio, apostar por investigar las estrategias de la diferencia (García González, 2000).

Sin embargo, para la época moderna todavía hay un gran déficit en la aplicación de este tipo de metodologías. En primer lugar, porque la mayor parte de las iniciativas tienen un sesgo más contemporáneo ${ }^{13}$; y, en segundo lugar, porque, cuando se ha hecho, los estudios se han centrado casi de forma exclusiva en las élites y grupos de poder o, en menor medida, entre comerciantes, clero o personal de la administración (Pérez García, 2004; Chacón, Roigé y Rodríguez, 2006). Aun en la actualidad, sin embargo, sabemos muy poco sobre los "sin tierra" (Lanzinger y Clemens, 2020; González Beltrán, 2017) o los pequeños propietarios y la gente corriente (Moriceau, 2017), sus estrategias de supervivencia y reproducción y sus posibilidades de movilidad social. Sí se ha hecho un esfuerzo en los últimos años por estudiar a los criados y sirvientes (Boudjaaba y García González, 2017; Whittle, 2017; Fauve-Chamoux, 2009; Sarti, 2007; Sarasúa, 2005), un tema casi monopolizado para el mundo urbano. Además, su interés no es sólo para confirmar o no la tesis del life-cycle servant de Peter Laslett, sino también para profundizar en las relaciones de desigualdad y dependencia social, y avanzar en otras alternativas distintas de la clásica explicación del triunfo del capitalismo en el que los sirvientes eran excluidos para poner todo el énfasis en el protagonismo de los terratenientes frente a los jornaleros.

Los déficits en el estudio de la reproducción demográfica y social diferencial implican integrar convenientemente el estudio de los comportamientos individuales y familiares y su relación con las dinámicas sociales. Para ello, desde el linkage nominativo hay que apostar de forma decidida por el análisis de datos transversales y longitudinales, de redes y genealogías colectivas, de trayectorias e itinerarios vitales, de lazos inter e intrageneracionales. Pensamos que aún no se ha explorado del todo la importancia de la edad y el 
curso de vida (García González e Irles Vicente, 2016) para la comprensión de los procesos de diferenciación social; por ejemplo, vinculando el ciclo vital y familiar con las estrategias de transmisión, distribución y concentración de la propiedad. Con harta frecuencia se sigue incidiendo exclusivamente en las primeras fases del ciclo familiar con el matrimonio y en el final, con la disolución de la pareja y la redistribución de los bienes a través del sistema de herencia. Igualmente, consideramos que, a la hora de estudiar la desigualdad, no se ha tenido en cuenta la duración. Además del conocimiento de la situación de una persona y de una familia en un momento dado, lo que importa es saber la duración de dicha situación y las posibilidades de cambio y movilidad a lo largo del tiempo.

Ligados al curso de vida están la movilidad social intergeneracional y el destino de los hijos (Irigoyen, 2019). Se trata de un destino en absoluto exento de tensiones, de tal modo que se está avanzando en matizar el discurso mecanicista que se ha solido imprimir al concepto de estrategia para poner de relieve también la importancia del disenso y la desobediencia (Blanco Carrasco, 2016, 2019; Alfaro, 2019). Los incipientes estudios sobre la juventud, alejados de la clásica formulación de la historia de las mentalidades, pueden encajar en esta dirección (Blanco Carrasco, García Fernández y Olival, 2019). Y en el otro extremo, también están apareciendo trabajos sobre la vejez con planteamientos muy distintos de los tradicionales (Botelho y Thane, 2001; García González, 2005; Dubert, Hernández y Andrade, 2007; Dubert, 2008). En este punto, si antes hemos comentado la importancia del parentesco -consanguíneo o espiritual o ficticio- en momentos como el bautismo, el matrimonio o la sucesión, también hay que insistir en cómo éstos o los lazos de amistad y vecindad se movilizaban en los períodos de crisis familiar (muerte, viudedad, enfermedad o tutela).

Los sistemas de ayuda y de solidaridad, u otro tipo de mecanismos informales de asistencia y cuidado, se están convirtiendo en otro tema que conviene desarrollar (Moring, 1997; Fernández Cortizo, 2015). Primero, con una mirada distinta de la que ha primado hasta ahora porque, o bien se consideraba que era un asunto que pertenecía a la familia sin más -con lo cual no era necesario explicitarlo ni investigarlo por obvio y sobreentendido-, o bien el interés se reducía a los medios establecidos por las instituciones.

Es cierto que en los estudios de historia de la familia se insiste mucho menos en su vertiente conflictiva y de ruptura (Vintilă-Ghițulescu, 2009; García González, 2016b; Guzzi, 2014). Por el contrario, se insiste en una versión "familista", sentimentalista y altruista, en los lazos de ayuda, pero no en los límites de la solidaridad ni tampoco, como contrapartida, en la dependencia y obligaciones que esconden. Los estudios de familia han avanzado de forma considerable en función de los dos polos que la enmarcaban e intervenían, el Estado y la Iglesia, entre las normas que generaban y su vulneración, especialmente en todo lo relacionado con el matrimonio. Pero convendría revisitar también el papel jugado por la comunidad (Pérez Álvarez y Rubio, 2014), muchas veces contemplada aún a la luz de aquellos estudios de la historia de las mentalidades, que insistía en la estrechez de los lazos vecinales, en una cierta idea de "comunitarismo" primitivo y en la fuerza del "disciplinamiento" colectivo que anulaba al individuo. Sin embargo, poco sabemos sobre el individualismo en las sociedades rurales, reservado como un fenómeno exclusivo del mundo urbano. Se trata de una temática, pues, en la que es imprescindible profundizar.

Una línea de trabajo que abre nuevas posibilidades de investigación hacia el futuro es la soledad (Beauvalett, 2008; García González, 2020a). Las personas solas suponían una realidad que, con harta frecuencia, ha quedado oculta detrás de una determinada representación de la familia en el pasado. Pero vivir sin casarse no es una invención de nuestra modernidad (Sarti y Lanzinger, 2006; Lanzinger, 2016; Marco, 2017). Como comentamos, los hogares solitarios o encabezados por un solo miembro de la pareja tuvieron una significativa presencia en las sociedades rurales. Asumían, cuando los había, la gestión de sus casas y sus bienes sin dejar de afrontar la incertidumbre de su destino. En un contexto como el actual, donde la soledad se ha considerado la "enfermedad" de nuestras sociedades, es lógico que se esté intensificando la atención por las personas que viven en solitario. Castigadas por el desinterés de los científicos sociales, en estos momentos los estudios se están planteando desde ópticas más complejas que trascienden la mera consideración de sus particularidades demográficas. 
En especial, hay que resaltar que el protagonismo social de las viudas y, en general, de las mujeres "solas" al frente de sus hogares no fue nada desdeñable (Froide, 2005; Moring y Wall, 2017; García González y Contente, 2017) e, incluso, en no pocas ocasiones, similar o superior al registrado en muchos núcleos urbanos o semiurbanos. Entre otras cuestiones, porque vivir en soledad no es necesariamente sinónimo de vejez, como tampoco de dependencia. Se han reproducido imágenes hasta la saciedad de la viuda pobre, desvalida y desamparada. Sin embargo, además de repensar el papel de las mujeres en los procesos de transmisión, se está revalorizando su importancia dentro de las economías familiares así como su múltiple y plural abanico de actividades (Rey Castelao, 2015, para el campo; y para la ciudad, Schmidt y Van der Heijden, 2016) o su capacidad no sólo para afrontar el reto de la supervivencia, sino también de emprendimiento al asumir la jefatura del hogar. Eso no quita que, entre los emigrantes, la incertidumbre de un regreso nunca asegurado conllevara que sus esposas no supieran si sus maridos seguían vivos o no; que a los recelos ligados a la distancia, con la posibilidad de amancebamientos, bigamia y otras formas de divorcio de facto, se sumaran las demandas de madres de familia abandonadas o de viudas que luchaban por el reconocimiento de sus derechos sobre los bienes propios o los pertenecientes a la sociedad conyugal; o que, junto a los incumplimientos de los esponsales, se diera la difusa situación de las “penélopes vírgenes" (Fajardo Spínola, 2020, p. 186) que seguían esperando a sus pretendientes. Dada la diversidad de situaciones objetivas que caracterizaba la existencia de quienes habían perdido su consorte, hay que descartar una visión homogénea. Frente al manto uniformador del estereotipo (García González, 2020b), para estudiar la soledad conviene aplicar una perspectiva de análisis diferencial que atienda a sus particularidades de estatus, actividad, riqueza y condiciones objetivas de existencia, además del sexo, el estado civil y el ciclo vital y familiar, según fuera en el mundo rural o en el mundo urbano. Lo que ocurre es que sabemos muy poco de los hombres solos. En parte debido a la vitalidad de la historia de "la familia en femenino" (Ramos Cabano, 2016) y en parte porque parece que los investigadores se han contagiado de esos tópicos que vinculan el matrimonio con el sedentarismo propio del mundo rural mientras que no interesa el solitario, el soltero, considerado una excepción y, además, algo exógeno, emblema del emigrante, del desarraigado y del vagabundo. Y ello a pesar de que obras como las de Rosental (1999) demuestran que, casados o no, el movimiento y no un mundo ruralsedentario era lo que predominaba en el pasado. Se observa, en consecuencia, un gran desequilibrio entre el interés demostrado por las mujeres frente al manifestado por los hombres solos y, entre ellas, por las viudas ante al resto de mujeres solas, así como entre las que vivían en la ciudad frente a las que vivían en el campo (García González, 2017).

Para finalizar, consideramos que todas las posibilidades que se abren con los nuevos planteamientos y temas expuestos se multiplicarían si dirigimos nuestros esfuerzos hacia una efectiva historia comparada a nivel internacional que supere los tradicionales límites nacionales con los que habitualmente han trabajado los investigadores ${ }^{14}$. El camino está trazado y el tejido asociativo preparado pero el reto está en ponerlo en práctica más allá de reunir estudios de un lado y otro de los Pirineos, de los Alpes o del Canal de la Mancha, de un lado y otro del Atlántico, etc.

\section{ConCLuSIón}

A tenor de los resultados expuestos, hemos comprobado el alejamiento existente entre la historia rural y la demografía histórica y la historia de la familia. La excesiva especialización académica parece haberse traducido en un cierto aislacionismo, pero además la época moderna ha quedado reducida a un lugar muy subsidiario al primar un sesgo totalmente contemporáneo y económico.

Si es cierto que los estudios no dejaron de crecer hasta finales de los años 80, en paralelo a la reciprocidad historiográfica existente entre la demografía histórica y la historia rural que dio lugar a un potente modelo agrodemográfico de investigación, después se entró en una fase de rendimientos decrecientes y de escasa productividad por su excesiva reiteración. A partir de entonces, estos trabajos fueron estigmatizados y, para muchos, considerados como una antigualla historiográfica. 
Sin embargo, como hemos puesto de manifiesto en este artículo, aun asumiendo que queda mucho por hacer, hay que reconocer que no sólo se está llevando a cabo una renovación profunda en algunos aspectos. También se están produciendo importantes avances con la aplicación de herramientas teóricas y metodológicas muy novedosas. El desarrollo durante estas dos últimas décadas de lo que podemos denominar la historia social de la población a partir de la consolidación de la historia de la familia como línea de investigación ha abierto un panorama lleno de nuevas posibilidades. Entre otras cuestiones, porque ha dado lugar a la revisión de rígidos planteamientos para dar respuesta a otro tipo de interrogantes acordes a los intereses e inquietudes actuales. Sin renegar de las enseñanzas de aquella historia rural agrodemográfica que estuvo a la vanguardia de la renovación de la historiografía europea, se ha ido avanzando hacia nuevas metodologías más integradoras e interdisciplinares que permitirán la articulación de un discurso muy diferente que no justifique el estudio del mundo rural del pasado como algo trasnochado e inútil para la comprensión de nuestro presente y para repensar nuestro futuro.

\section{REFERENCIAS}

Alfani, G. (2010). Climate, population and famine in Northern Italy: General Tendencies and Malthusian Crisis, ca. 1450-1800. Annales de Demographie Historique, 120(2), 23-53.

Alfani, G. y Gourdon, V. (Eds.). (2012). Spiritual Kinship in Europe, 1500-1900. Houndmills: Palgrave Macmillan.

Alfani, G., Gourdon, V., Munno, C. y Robin, I. (2018). Parrainage et compérage: de nouveaux outils au service d'une histoire sociale des espaces européens et coloniaux. En Dosier Parrainage et compérage à l'époque moderne, Histoire, économie \& société, 37e année(4), 4-17. http://dx.doi.org/10.3917/hes.184.0004

Angulo Morales, A. (2015). Los frutos de la movilidad. La emigración norteña peninsular en Madrid y el Imperio (siglos XVII y XVIII). Obradoiro de Historia Moderna, 24, 113-139. http://dx.doi.org/10.15304/ohm.24.2708

Ardit i Lucas, M. (1999). Microanálisis demográfico en larga duración: el caso de España. En M. González Portillay K. Zarraga (Eds.), Actas del IV Congreso de la Asociación de Demografía Histórica. II. Pensamiento demográfico, coyuntura y microanálisis (pp. 253-307). Bilbao, España: Universidad del País Vasco.

Bartolomé Bartolomé, J. M (2009). “Las prácticas hereditarias en la provincia de León: cantidades y bienes que escapan al reparto igualitario y las legítimas (1700-1850). Revista de Demografía Histórica, 27(1).

Béaur, G. (2017). Gestionar la transmisión del patrimonio: las familias y sus estrategias de reproducción social en la Francia rural, siglos XVI-XIX. Obradoiro de Historia Moderna, 26, 9-43.

Béaur, G. (Coord.) (2011). Dosier Le contrat de mariage, Annales de démographie historique. 1(121).

Birgy, O. (2014). Une occupation originale de l'espace rural. La communauté anabaptiste de Normanvillars dans le Sundgau au XVIIIe siècle. Histoire et Societés Rurales, 41(1), 17-54.

Birriel Salcedo, M. (Ed.) (2017). La(s) casa(s) en la Edad Moderna. Zaragoza: Institución Fernando el Católico.

Blanco Carrasco, J. P. (2012a). Migraciones pendulares en la Península Ibérica durante la época moderna. Notas acerca del papel de la trashumancia en la determinación del sistema migratorio de la España interior. Estudios bumanisticos. Historia, 11, 121-146.

Blanco Carrasco, J. P. (2012b). "Consanguinidad, exogamia y estrategias colectivas en la sociedad moderna. Reflexiones en torno a un ejemplo rural (1700-1820). Revista de Demografía Histórica, 30(2).

Blanco Carrasco, J. P. (2016). Disensos. Conflictos de la patria potestad en la España rural moderna. En F. García González (Coord.), Dosier Crisis familiares y curso de vida en la España Moderna Studia historica. Historia moderna, 38(2), 107-135.

Blanco Carrasco, J. P. (2019). Notas sobre la desobediencia intergeneracional durante los últimos compases de la España Moderna. En A. Irigoyen López(Coord.), Dosier Hijos y padres en la España del Antiguo Régimen: individualismo y estrategias familiares. Tiempos modernos: Revista Electrónica de Historia Moderna, 9(38).

Blanco Carrasco, J. P., García Fernández, M., y Olival, F. (Coords.), (2019). Jóvenes y juventud en los espacios ibéricos durante el Antiguo Régimen. Vidas en construcción. Lisboa: Ediçoes Colibri. 
Botelho, L. y Thane, P. (2001). Women and ageing in British society since 1500. N York: Routledge.

Boudjaaba, F. (2005). Parenté, alliance et marché dans la France ruale traditionnelle. Essai d'application de l'analyse de réseaux au marché foncier et immobilier de Saint-Marcel (Normandie) 1760-1824. Annales de Démographie Historique, 109(1),33-59.

Boudjaaba, F. (2008). Des paysans attachés à la terre? familles, marchés et patrimoines dans la région de Vernon (1750-1830). París: PUPS.

Boudjaaba, F. (2016). Familia, propiedad y reproducción social en el medio rural en Francia: una historiografía profundamente renovada. En F. García González, G. - Béaur y F. Boudjaaba (Eds.), La historia rural en Españay Francia (siglos XVI-XIX). Contribuciones para una historia comparada y renovada (pp. 319-336). Zaragoza: PUZ.

Boudjaaba, F. y Arrizabalaga, M. P. (2015). Les systèmes familiaux. de la cartographie des modes d'héritage aux dynamiques de la reproduction familiale et sociale. Annales de démographie historique, 1(129), 165 à 199

Boudjaaba, F. y García González, F. (Coords.) (2017). Dosier El trabajo doméstico y sirviente en la Europa rural (SS. XVI-XIX). Diversidad de modelos regionales y formas de dependencia. Mundo Agrario, 18(39).

Bourdelais, P. y Gourdon, V. (2000). L'histoire de la famille dans les revues françaises (1960-1995): la prégnance de l'anthropologie. Annales de Demographie Historique, 2, 25-30.

Breschi, M., Derosas, R. y Viazzo, P. P. (Eds.) (2003). Piccolo è bello. Approcci microanalitici nella ricerca storicodemografica. Udine: Forum.

Brunet, G. et al (2008). Patronymes, propriété et mobilité géographique. L'avant-pays savoyard du XVIIIe au XXe siècle. Histoire et Société Rurales, 30()67-90.

Buon, J. (2008). Conceptions prénuptiales et non-respect des règles de la religion à Saint-Pol-sur-Ternoise, 1676-1844. Annales de Demographie Historique, 116(2),237-256.

Capdevila, A. (2004). La immigració francesa. Un factor decisiu de la recuperació demogràfica la comarca del Maresme a l'època moderna?. Estudis d'Historia Agraria, 17, 231-242.

Castellani, L. (2010). Maison et habitat dans la Balagne rurale littorale du début du XVIIIe à la fin du XIXe siècle. Histoire et Société Rurales, 34(2), 79-108.

Chacón Jiménez, F. (2009). Patrimoine et mariage Systèmes héréditaires et transformations sociales dans l'Europe méditérranéenne (XV-XVIIIe siècles). En S. Cavaciocchi(Coord.), La famiglia nell'economia europea, secoli XIIIXVIII (pp. 69-80). Firenze: Firenze University Press.

Chacón Jiménez, F., Roigé, X., Rodríguez, E. (Eds.). (2006). Familias y poderes. Actas del VII Congreso Internacional de la ADEH. Granada, España: Universidad de Granada.

Clark, P. (2000). British Clubs and Societies 1580-1800: The Origins of an Associational World. Oxford: Oxford University Press.

Congost Colomer, R. (2014). Més enllà de les etiquetes. Reflexions sobre l'anàlisi dels grups socials humils. La regió de Girona (1770-1850). Recerques: història, economia, cultura 68, 165-191.

Cook, K. P. (2016). Forbidden Passages. Muslims and Moriscos in Colonial Spanish America. Pennsylvania: University of Pennsylvania Press.

Croix, A. (1999). L'ouverture des villages sur l'extérieur fut un fait éclatant dans l'ancienne France. Position de thèse. Histoire et Sociétés Rurales, 11, primer semestre, 109-146.

Dosier. (2001). La transición demográfica en España y Portugal. Revista de Demografía Histórica, 19(2).

Dosier. (2001). Migrazioni. Quaderni storici, 36(106).

Dosier. (2002). Les migrations au scalpel. Annales de Démographie Historique, 2(104).

Dosier. (2002). Redes migratorias y migraciones internas. Revista de Demografía Histórica, 20(1).

Dosier. (2009). Els capítols matrimonials en el món rural. Estudis d'història agrària, 22.

Dubert, I. (2002). Las dinámicas demográficas de las pequeñas villas gallegas a finales del Antiguo Régimen. Obradoiro de Historia Moderna, 11. 
Dubert, I. (2005). De la géographie des structures familiales aux stratégies adaptatives des familles en Espagne 1752-1860. Annales de Démographie Historique, 109(1), 199-226.

Dubert, I. (2008). Vejez, familia y reproducción social en España, siglos XVII-XX. Revista de Demografía Histórica, $26(2), 87-122$.

Dubert, I. (2015a). La demografía de la época moderna en España. Una perspectiva comparada, 1980-2012. En O. Rey Castelaoy F. Suárez (Eds.), Los vestidos de Clío. Métodos y tendencias de la historiografía modernista española (1973-2013) (pp. 111-147). Santiago de Compostela: Universidad de Santiago de Compostela.

Dubert, I. (Coord.) (2015b). Dosier De la demografía histórica a la historia social de la población, Obradoiro de historia moderna, 24.

Dubert, I. y Gourdon, I. (Eds.) (2017). Inmigración, trabajo y servicio doméstico en la Europa urbana, siglos XVIII-XX. Madrid: Casa de Velázquez.

Dubert, I., Hernández Borge, J. y Andrade Cernadas, J. M. (Coords.) (2007). Dosier Vejez y Envejecimiento en Europa Occidental, Semata: Ciencias sociais e humanidades, 18.

Dupâquier, J. (2002). Sédentarité et mobilité dans l'ancienne société rurale. Enracinement et ouverture: faut-il vraiment choisir? Histoire et Société Rurales, 18(2), 121-135.

Eibach, J. y Lanzinger, M. (Coords.) (2020). The Domestic Sphere in Europe (16th to 19th century). London: Routledge History.

Eiras, Roel, A. (2004). Demografía rural en la España moderna: evolución, variantes y problemas. En J. Aranda Pérez (Coord.), El Mundo Rural en la España Moderna. Vol. II (pp. 19-78). Cuenca: Universidad de Castilla-La Mancha.

Fajardo Spínola, F. (2020). Las viudas de los emigrantes canarios a América (1680-1830). Entre la esperanza, la soledad y el abandono. En F. García González (Ed.), Vivir en soledad. Viudedad, soltería y abandono en el mundo rural (España y América Latina, Siglos XVI-XXI). (pp. 179-204). (Madrid: Iberoamericana Vervuert.

Fauve-Chamoux, A. (Coord.) (2009). Domesticité et parcours de vie. Annales de démographie historique, Vol. 1, No 117.

Fernández Cortizo, C. (2015). "En el mundo que hemos perdido". Padres ancianos e hijos en la Galicia occidental en el siglo XVIII. Obradoiro de historia moderna, No 24, 195-224.

Ferrer i Alós, Ll. (2007). Una revisió del creixement demogràfic de Catalunya en el segle XVIII a partir dels registres parroquials. Estudis d'Historia Agraria, Vol. 20, 17-68.

Ferrer i Alós, Ll. (2011). Acceso y distribución a los medios de producción. Herencia y reproducción social. En F. Chacón Jiménez y J. Bestard. Familias. Historia de la sociedad española (pp. 255-324). Madrid: Cátedra.

Fontaine, L. (2005). Montagnes et migrations de travail. Un essai de comparaison globale (XVe-XXe siècles). Revue d'Histoire Moderne et Contemporaine, 52(2), 26-48.

Fornasin, A. y Zannini, A. (Eds) (2002). Uomini e comunità delle montagne. Paradigmi e specificità del popolamento dello spazio montano. Udine: Forum.

Froide, A. M. (2005). Never married: single women in early modern England. Oxford: Oxford University Press .

García Fernández, M. (2017). Revistiendo el interior de los espacios domésticos populares. Cultura material y cotidiana: permanencias y evoluciones. En M. Birriel Salcedo (Ed.), La(s) casa(s) en la Edad Moderna (pp. 93-124). Zaragoza: Instituto Fernando el Católico.

García González, F. e Irles Vicente, M. C. (2016). Dosier Curso de Vida y Reproducción Social en España y en Europa en la Edad Moderna, Revista de Historia Moderna, 34.

García González, F. y Contente, C. (Eds.). (2017). Mujeres al frente del hogar en perspectiva histórica, ss. XVIII-XXI. Revista de Historiografia, 26.

García González, F. y Gómez Carrasco, C. J. (2008). Parentesco ficticio y red social en la España meridional (Albacete, 1750-1808).Popolazione e Storia, 9(1), 35-54.

García González, F. (2000). Las estrategias de la diferencia. Familia y reproducción social en la Sierra (Alcaraz, siglo XVIII). Madrid: Ministerio de Agricultura. 
García González, F. (2005). Vejez, envejecimiento e historia. La edad como objeto de investigación. Introducción. En F. García González (Coord.),Vejez, envejecimiento y sociedad en España, siglos XVI-XXI (pp. 11-34). Cuenca: Universidad de Castilla-La Mancha.

García González, F. (2007). La historia de la familia en el mundo rural. La contribución del Seminario Familia y Élite de Poder y de la Asociación de Demografía Histórica. En F. Chacón y J. Hernández Franco (Eds.), Espacios sociales, universos familiares. La familia en la historiografía española (pp. 107-136). Murcia: Ediciones de la Universidad de Murcia.

García González, F. (2011). Las estructuras familiares y su relación con los recursos humanos y económicos. En F. Chacón y J. Bestard (Coords.), Familias. Historia de la sociedad española (del final de la Edad media a nuestros días) (pp. 159-254). Madrid: Cátedra.

García González, F. (2014). El estudio de la sociedad rural en la España Moderna, ¿una antigualla historiográfica? En F. García González (Coord.), Dossier Familia y sociedad rural en la España del Antiguo Régimen, Tiempos Modernos. Revista on-line de Historia Moderna, Vol. 8, № 29/2.

García González, F. (2015). Investigar historia rural en España y Francia en la época moderna. Impulso y renovación desde la historia comparada. En O. Rey Castelao y F. Suárez (Eds.), Los vestidos de Clío. Métodos y tendencias de la historiografia modernista española (1973-2013) (pp. 171-203). Santiago de Compostela: Universidad de Santiago de Compostela.

García González, F. (2016a). "Familia, desigualdad y reproducción social en la España rural, siglos XVI-XIX: un balance historiográfico (2000-2014)”, García González, F. - Béaur, G. - Boudjaaba, F. (Eds.). La historia rural en España y Francia (siglos XVI-XIX). Contribuciones para una historia comparada y renovada. Zaragoza: PUZ, pp. 271-318.

García González, F. (2017). Mujeres al frente de sus hogares. Soledad y mundo rural en la España interior del Antiguo Régimen. En F. García Gonzálezy C. Contente (Eds.), Mujeres al frente del hogar en perspectiva histórica, ss. XVIIIXXI. Revista de Historiografia, 26, 19-46.

García González, F. (2020b). Las mujeres solas en la España rural. Sobre tópicos y estereotipos en perspectiva histórica. E F. García González (Ed.), Vivir en soledad. Viudedad, soltería y abandono en el mundo rural (España y América Latina, Siglos XVI-XXI) (pp. 239-270). Madrid: Iberoamericana Vervuert.

García González, F. (Ed.) (2016b). Dosier Crisis familiares y curso de vida en la España Moderna. Studia Historica. Historia Moderna, 38(2).

García González, F. (Ed.). (2020a).Vivir en soledad. Viudedad, soltería y abandono en el mundo rural (España y América Latina, Siglos XVI-XXI). Madrid: Iberoamericana Vervuert.

García González, F. y Crespo Sánchez, F. J. (2017). Radiografía de un impulso compartido. La historia de la familia en España e Iberoamérica (2000-2015). En O. Rey Castelao y P. Cowen (Eds.), Familias en el Viejo y el Nuevo Mundo (pp. 44-78). La Plata: Universidad Nacional de La Plata.

García González, F., Béaur, G. y Boudjaaba, F. (2016). (Eds). La historia rural en España y Francia (siglos XVI-XIX). Contribuciones para una historia comparada y renovada. Zaragoza: PUZ.

Garofalo, L. J. (2017). The Shape of a Diaspora. The Movement of Afro-Iberians to Colonial Spanish America. En K. B. Sherwin y R. S. O'Toole (Eds.), Africans to Spanish America: Expanding the Diaspora. University Press Scholarship Online. http://dx.doi.org/10.5406/illinois/9780252036637.003.0001

González Beltrán, J. M. (2017). Entre surcos y penurias. Asalariados del campo en la Andalucia occidental del siglo XVIII. Cádiz: Universidad de Cádiz.

González de Molina, M. (2012). Repensar la historia agraria. Debates SEHA. Recuperado de http://seha.info/7/Rep ensar_la_Historia_Agraria.pdf

Hernández López, C. (2013). La casa en La Mancha oriental. Arquitectura, familia y sociedad rural (1650-1850). Madrid: Sílex.

Iriarte Goñi, I. (2013). Repensar la historia agraria. Reflexiones en torno al texto de Manuel González de Molina”. Debates SEHA. Recuperado de http://seha.info/7/Debates_SEHA_Inaki.pdf 
Lanzinger, M. (2016). Soltería: contextos, impactos y trayectorias en la Europa Central (siglos XVIII y XIX). En F. García González y M. C. Irles Vicente (Coords.), Dosier Curso de vida y reproducción social en España y en Europa en la Edad Moderna. Revista de historia moderna, № 34, 61-77.

Lanzinger, M.y Clemens, Z. (Eds.). (2020). Dosier Landlos, en Zeitschrift für Agrargeschichte und Agarsoziologie, 68(1). Llopis Agelán, E. et al. (2012). La debilidad demográfica de un territorio de la España interior. La población de Guadalajara, 1530-1860. Historia Agraria, No 57, 13-45.

Marco Gracia, F. J. (2017). Los solteros frente a su destino. Vida y muerte de las solteras y los solteros rurales en el valle del Ebro (1700-2012). Revista de Demografía Histórica, Vol. 35, No 1, 121-148.

Martínez Carrión, J. M. y Pinilla, V. (2017). Historia Agraria. Revista de agricultura e historia rural. Documentos de Trabajo DT-SEHA 1707, noviembre

Merzario, R. (1981). Il paese stretto. Strategie matrimoniali nella diocesi di Como, Secoli XVI-XVIII. Turín: Giulio Einaudi.

Mikelarena Peña, F. y Erdozáin, M. P. (2002). Evolución demográfica y crisis de mortalidad en las Cinco Villas de la montaña navarra entre 1700 y 1860. Revista de Demografía Histórica, Vol. 20, $\mathrm{N}^{\circ} 1$.

Minville, S. (2016). "Migraciones y movilidad en el mundo rural en Francia (siglos XVI-XIX)”, en García González, F. - Béaur, G. - Boudjaaba, F. (Eds.), La historia rural en España y Francia (siglos XVI-XIX). Contribuciones para una historia comparada y renovada. Zaragoza: PUZ, pp. 57-77

Moreno Navarro, I. y Palenzuela Chamorro, P. (2000). Jornaleros y campesinos como colectivos identitarios en Andalucía., En M. González de Molina (Ed.), La Historia de Andalucía a debate. Vol. I. Campesinos y jornaleros. Una revisión historiográfica (pp.223-238). Granada: Anthropos.

Moriceau, J. M. y Madeline, Ph. (Eds.) (2017). Les petites gens de la terre: Paysans, ouvriers et domestiques (Moyen Age - XXIe siècle). Caen: Presses Universitaires de Caen.

Moring, B. y Wall, R. (2017). Widows in European Economy and Society, 1600-1920. Woodbridge: Boydell Press.

Moring, B. (1997). "Estrategias familiares, sistemas hereditarios y el cuidado de los ancianos en Finlandia oriental y occidental desde una perspectiva histórica., Revista de Demografía Histórica, Vol. 15, N 2, 113-134.

Oris, M. (Coord.) (2008). Dossier Reproduction différentielle et dynamiques sociales, Annales de démographie bistorique, $1(115)$.

Palm, L. y Schott, R. (2001). Le changement caché du système démographique suédois à «l'Époque de la Grandeur». Des mariages adolescents aux mariages tardifs. Annales de Demographie Historique, 102(2), 141-172.

Paping, R. y Collenteur, G. (2004). Population growth and social structure in a market-oriented agricultural economy in the Netherlands, 1750-1820., Obradoiro de Historia Moderna, Vol. 13.

Pérez Álvarez, Ma J. (2005). Modelos socioeconómicos en la provincia de León: la Montaña y Tierra de Campos en el siglo XVIII". Studia Historica. Historia Moderna, Vol. 27, 241-273.

Pérez Álvarez, Ma J. y Rubio Pérez, L. (2014). Familia y comunidad rural. Modelos agrarios, colectivismo social y comportamientos familiares en la provincia de León durante la Edad Moderna. Studia Historica. Edad Moderna, Vol. 36.

Pérez García, J. M. (2009). Las claves de la euforia demográfica del Bajo Miño a través de San Martín de Caldelas (1580-1680). Revista de Demografía Histórica, Vol. 27, № 2.

Pérez García, J. M. (Ed.) (2004). Dosier Movilidad y familia: Estrategias de reproducción y movilidad social. Revista de Demografía Histórica, XXII-I, Vol. 22, No 1.

Poska, Allyson M. (2016). Gendered Crossings. Women and Migration in the Spanish Empire.Albuquerque: University of New Mexico Press.

Pozzi, Lucia (Ed.) (2007). Dosier 1977-2007. I trent'anni della Società italiana di demografia storica. Popolazione e storia, $8(2)$.

Quemener, P. (2018). Parrainage et solidarités en basse Auvergne au XVIe siècle, Dosier Parrainage et compérage à l'époque moderne. Histoire, économie \& société, 4, 18-37. http://dx.doi.org/10.3917/hes.184.0018 
Ramos Cobano, C. (2016). La familia en femenino. Prácticas sociales y relaciones de género entre los Cepeda en la tránsito a la contemporaneidad. Madrid: Fundación Española de Historia Moderna.

Rao, R. (2009). Villaggi abbandonati nel Vercellese: due crisi a confronto (secoli XIV-XVII). Popolazione e Storia, $10(1), 39-56$.

Rappo, L. (2019). Matrimonial alliances in Corsier-sur-Vevey (Switzerland) during the 18th and 19th centuries: an evolution towards close kin. F. García González, y M. Gasperoni (Coords). Dosier La sangre y el parentesco: Representaciones y prácticas sociales de la consanguinidad (Edad Media y Época Moderna), Revista de Demografía Histórica, 2, 119-156.

Rey Castelao, O. (2008). Las migraciones femeninas de Antiguo Régimen en su contexto europeo. En J. Hernández Borge y D. González Lopo (Eds.), Mujer y emigración. Una perspectiva plural, Santiago de Compostela (pp. 39-68). Santiago de Compostela: Universidad de Santiago.

Rey Castelao, O. (2015). El trabajo de las mujeres rurales en la España Moderna. Un balance historiográfico, 1994/2013. Revista de Historiografía, 22, 183-210.

Rey Castelao, O. (2016). Población, ocupación del territorio y migraciones rurales en la bibliografía española reciente. En F. García González, - G. Béaur y F. Boudjaaba (Eds.), La historia rural en España y Francia (siglos XVI-XIX). Contribuciones para una historia comparada y renovada (pp. 35-55). Zaragoza: PUZ.

Rosental, P. A. (1999). Les sentiers invisibles. Espace, familles et migrations dans la France du XIX siècle. París: Éditions de la EHESS.

Ruggiu, J. P. (2007). L'individu et la famille dans les sociétés urbaines anglaise et française (1720-1780). París: PUPS.

Saito, O. (1997). Demografía histórica: Realizaciones y expectativas. Revista de Demografia Histórica, Vol. 15, N² 169-204.

Salas Auséns, J. A. (2004).Inmigrantes en una tierra de emigración. Extranjeros en Galicia en la segunda mitad del siglo XVIII". Obradoiro de Historia Moderna, 13, 163-193.

Salas Auséns, J. A. (2015). Pero si..., y si..., por si...: asegurar la pervivencia de la casa en el alto Aragón en la Edad Moderna., Obradoiro de historia moderna, № 24, 225-255.

Salas Auséns, J.A. (1999). En busca de El Dorado: inmigración francesa en la España de la Edad Moderna. Bilbao: Universidad del País Vasco.

Sarasúa, C. (Coord.) (2005). Dosier Criados y mozos en la organización histórica del trabajo agrario. Historia Agraria, XII, 35.

Sarti, R. y Lanzinger, M. (Eds.) (2006). Nubili e celibi tra scelta e costrizione: secoli XVI-XX. Udine: Forum.

Sarti, R. (2007). Criados, servi, domestiques, gesinde, servants: for a comparative history of domestic service in Europe (16th-19th centuries). Obradoiro de Historia Moderna, No 16, 9-39.

Schmidt, A. y van der Heijden, M. (2016). Women Alone in Early Modern Dutch Towns: Opportunities and Strategies to Survive.- Journal of Urban History, 42(1), 21-38.

Seijas, T. (2014). Asian Slaves in Colonial Mexico. From Chinos to Indians. Nueva York: Cambridge University Press.

Skorepová, M. (2018). Le parrainage en Bohême dans le milieu rural, du xvie au xixe siècle, en Dosier Parrainage et compérage à l'époque moderne. Histoire, économie \& société, 4, 106-122. http://dx.doi.org/10.3917/hes.184.0 106

Sobrado, H. (2001). « Heredero único y familia troncal en la Galicia interior, 1750-1860, Studia Historica. Edad Moderna, vol. 23.

Tullio, M.y Lorenzini C. (Eds.) (2014). Dosier Per linee orizzontali. Parentela e famiglia in Italia settentrionale in età moderna, Popolazione e Sotoria, Vol. 15, $\mathrm{N}^{\circ} 1$.

Viazzo, P. P. (2007). Struttura e cultura: la storia della popolazione italiana tra demografia e scienze social. Popolazione estoria, 8(2), 51-65.

Viazzo, P. P. (2009). Looking East What can historical studies of Eastern countries contribute to current debates on commonalities and divergences in family, kinship and welfare provision in Europe, past and present?. Popolazione e Storia, 10(2), 119-136. 
Vicedo, R. (2007). Les transformacions del món rural de les terres de Lleida. Els límits d'un creixement. Segle XVIII. Estudis d'Historia Agraria, 20, 69-88.

Villar García, M. P. y Pezzi, Cristóbal, P. (Eds.) (2003). Los extranjeros en la España Moderna. Málaga: Ministerio de Ciencia e Innovación, 2 vols.

Vintilă-Ghițulescu, C. (2009). Autour du divorce: disputes et réconciliations au tribunal (Valachie, 1750-1830). Annales de Démographie Historique, 118(2), 77-99.

Viret, J. L. (2008). La reproduction familiale et sociale en France sous l'ancien régime. Le rapport au droit et aux valeurs. Histoire et Société Rurales, Vol. 29, 2008/1, 165-188.

Whittle, J. (Ed.) (2017). Servants in Rural Europe, 1400-1900. Suffolk: Boydell Press

Zeller, O. (2007). Changement agraire et récession démographique: la première enquête Orry (1730). L'exemple de l'élection d'Issoudun. Annales de Demographie Historique, 114(2), 143-171. 


\section{ANEXO}

Cuadro 1. Proporción de articulos sobre el mundo rural de la Edad Moderna en algunas revistas europeas (2000-2014)

\begin{tabular}{|c|c|c|c|c|c|}
\hline REVISTA & $\begin{array}{l}\text { Artículos } \\
\text { sobre } \\
\text { mundo } \\
\text { rural }\end{array}$ & $\begin{array}{l}\text { Total } \\
\text { artículos } \\
\text { de la } \\
\text { revista }\end{array}$ & $\%$ & $\begin{array}{c}\text { Artículos sobre } \\
\text { familia y } \\
\text { demografia } \\
\text { rural }\end{array}$ & $\begin{array}{c}\% \text { sobre } \\
\text { artículos } \\
\text { mundo } \\
\text { rural }\end{array}$ \\
\hline $\begin{array}{c}\text { Histoire et Societés } \\
\text { Rurales }\end{array}$ & 61 & 160 & 38,1 & 10 & 16,4 \\
\hline $\begin{array}{c}\text { Estudis d'Historia } \\
\text { Agraria }\end{array}$ & 60 & 164 & 36,6 & 12 & 20 \\
\hline $\begin{array}{c}\text { Rural History } \\
\text { Journal }\end{array}$ & 38 & 180 & 21,1 & 6 & 15,8 \\
\hline $\begin{array}{c}\text { Revista de } \\
\text { Demografia } \\
\text { Histórica }\end{array}$ & 28 & 165 & 16,9 & 28 & 100 \\
\hline $\begin{array}{c}\text { Obradoiro de } \\
\text { Historia Moderna }\end{array}$ & 25 & 150 & 16,7 & 13 & 52 \\
\hline Historia Agraria & 43 & 270 & 15,9 & 5 & 11,6 \\
\hline $\begin{array}{c}\text { Popolazione e } \\
\text { Storia* }\end{array}$ & 12 & 86 & 13,9 & 11 & 91,7 \\
\hline $\begin{array}{c}\text { Annales de } \\
\text { Demographie } \\
\text { Historique }\end{array}$ & 34 & 250 & 13,6 & 32 & 94,1 \\
\hline $\begin{array}{l}\text { Studia Historica. } \\
\text { Historia Moderna }\end{array}$ & 13 & 180 & 7,2 & 3 & 23,1 \\
\hline Histoire et Mesure & 13 & 220 & 5,9 & 2 & 15,4 \\
\hline $\begin{array}{c}\text { Revista de Historia } \\
\text { Económica }\end{array}$ & 5 & 135 & 3,7 & & \\
\hline $\begin{array}{c}\text { Revue d'Histoire } \\
\text { Moderne Et } \\
\text { Contemporaine }\end{array}$ & 16 & 560 & 2,9 & 2 & 12,5 \\
\hline Hispania & 11 & 405 & 2,7 & & \\
\hline Historia Social & 8 & 308 & 2,6 & 3 & 37,5 \\
\hline Étude Rurales & 4 & 168 & 2,4 & 1 & 25 \\
\hline $\begin{array}{l}\text { Histoire, Economie } \\
\text { et Societé }\end{array}$ & 7 & 352 & 2 & 4 & 57,1 \\
\hline Revue Historique & 5 & 280 & 1,8 & & \\
\hline Total & 383 & 4033 & 9,5 & 132 & 34,5 \\
\hline
\end{tabular}


Nota: Los artículos de la revista Popolazione e Storia sólo se refieren al período 2007-2014

Figura 1. Red de co-ocurrencias de palabras clave de los articulos sobre demografía histórica y familia en WoS (2000-2019)

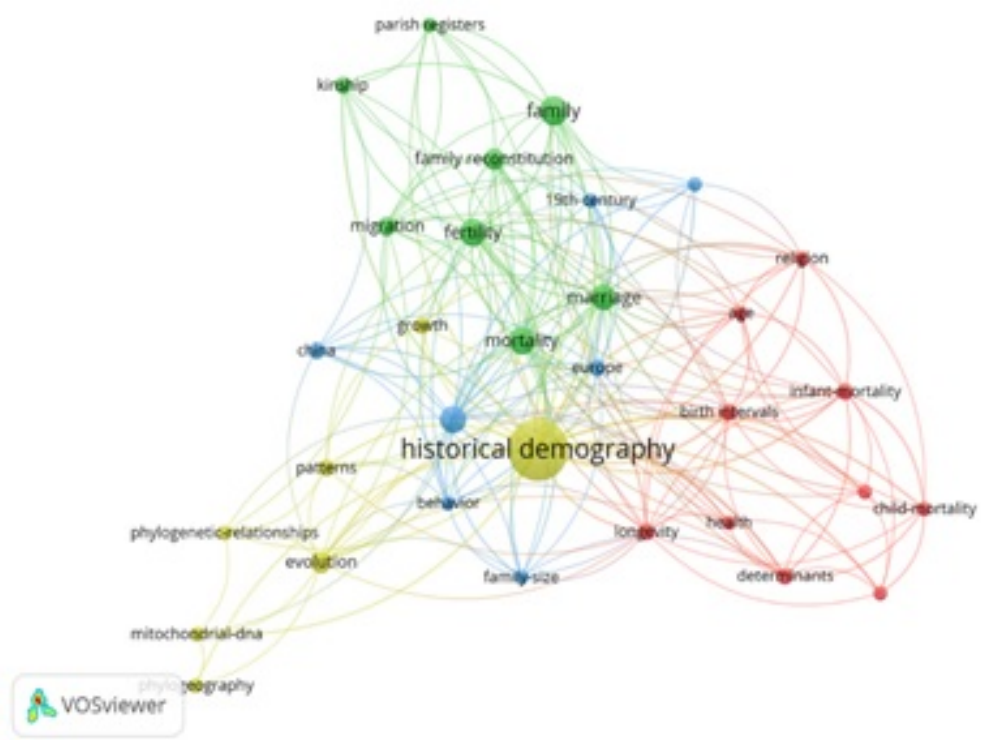

Figura 2. Red de co-ocurrencias de palabras clave de los artículos sobre historia rural en WoS (2000-2019)

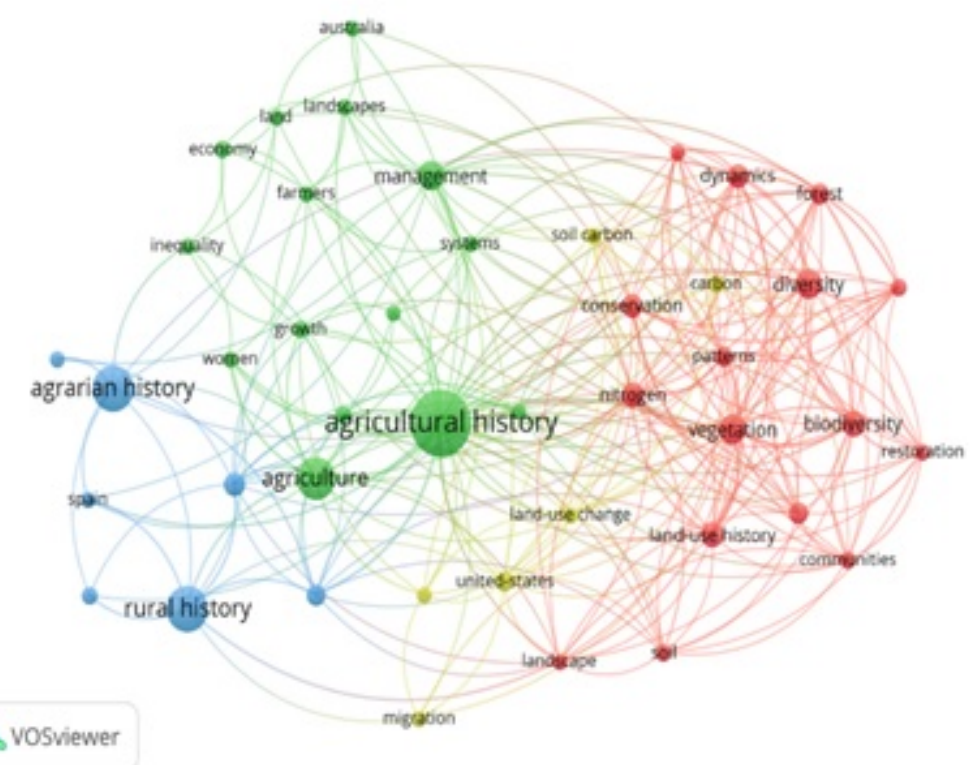




\section{Notas}

1 Este trabajo forma parte de los proyectos de investigación de Referencia HAR2017-84226-C6-2-P y PGC2018-094491B-C33 financiados por el Programa Estatal de Fomento de la Investigación Científica y Técnica de Excelencia del Gobierno de España. Y asimismo 20638/JLI/18 de la Fundación Séneca y del proyecto Europeo ERASMUS + KA226: 2020-1-ES01-KA226-HE-095430

2 Una aproximación reciente sobre el tema que nos ocupa para el caso de Francia en Boudjaaba (2016) y Minvielle (2016); para España en García González (2007, 2016a) y Rey Castelao (2016). En general, sobre tendencias evolutivas Boudjaaba, F. y Arrizabalaga (2015), Pozzi (2007), Dubert (2015a,b), García González y Crespo (2017).

3 Nuestra exploración la realizamos en dos fases. Durante la primera, se extrajeron los datos descriptivos para cuantificar las principales temáticas entre 2000 y 2019 en el paquete bibliometrix v. 1.9.4 de R. La segunda incluyó las conexiones entre los temas abordados por los artículos. Los mapas bibliométricos se construyeron usando VOSviewer, una herramienta específicamente diseñada para construir y visualizar este tipo de mapas.

4 Aunque sea un indicador muy burdo, si utilizamos como botón de muestra las comunicaciones presentadas en los tres congresos celebrados por la ESHD y nos fijamos en las que hacen alusión al término rural, los resultados obtenidos son muy significativos: en el primero (Alghero, 2014), "rural" solo aparece en cinco comunicaciones (de ellas solo una se plantea del siglo XVII al XIX); en el segundo (Lovaina, 2016) hay ocho (de las cuales solo la mitad inician su estudio en alguno de los siglos modernos y todas terminan en el siglo XIX); y finalmente, hay otras cinco en el tercer congreso (Pécs, 2019) pero solo dos comienzan su cronología a finales del siglo XVIII para finalizar, como el resto, en el XIX. Al contrario, si cambiamos de prisma y analizamos la definición de las sesiones presentadas en el último congreso de la EURHO (París, 2019), también en solo cinco de ellas el contenido se refiere a cuestiones relacionadas con la historia de la familia o la demografía histórica: la producción doméstica, el hogar, la herencia, el hambre o el poblamiento. La escasa conexión entre la demografía histórica y la historia rural que nos ofrecía el análisis de los metadatos de Web of Science se confirma de nuevo con esta sencilla comparación a partir del contenido de los congresos más recientes de ambas disciplinas.

5 Como afirman José Miguel Martínez Carrión y Vicente Pinilla (2017, p. 6) para la revista Historia Agraria, «el auge de Historia Agraria estuvo claramente relacionado con el impulso que la historia agraria tuvo entre los investigadores en historia económica e historia contemporánea. En ambos campos de conocimiento el estudio de las sociedades rurales se consolidó como un área relevante de estudio».

6 Como ejemplo valga el II Congreso Internacional sobre Transiciones en la agricultura y la sociedad rural organizado por la SEHA y Rural Report en Santiago de Compostela en junio de 2018: de las 37 sesiones paralelas que vertebraron el congreso, ninguna abordaba temáticas específicas de la demografía histórica y solo 3 se incluían dentro de la historia de la familia. Si analizamos lo ocurrido en el XII Congreso de la ADEH (Oporto, septiembre de 2019) en ninguna de las 57 sesiones paralelas desarrolladas aparece el término rural (ni campesino, agrario o similar).

7 Una necesidad que no pasa desapercibida para la European Society of Historical Demography como quedó de manifiesto en su último congreso (Pécs, Hungary, 26-29 Junio, 2019) al animar a los participantes a presentar propuestas teóricas y metodológicas.

8 Como botón de muestra véase el dosier dedicado a la transición demográfica en España y Portugal en la Revista de Demografía Histórica, 2001, 19(2), con artículos de Jesús Javier Sánchez Barricarte, Francisco Ramírez Gámiz o Norberta Amorim.

9 Un claro ejemplo de la complejidad al respecto es el caso español: además de los trabajos de Ferrer i Alós para Cataluña, véase Sobrado (2001) para Galicia, Salas Auséns (2015) para Aragón o Bartolomé (2009) para Castilla.

10 Una nueva mirada a fuentes tradicionales como los contratos de matrimonio en Béaur (2011), con artículos referidos a los casos de el Tirol, los Pirineos, Normandía, Cataluña y Rumanía. Igualmente, el dosier Els capítols matrimonials en el món rural, en Estudis d'história agrària (2009), con aportaciones sobre Cataluña y Francia.

11 Para algunos ejemplos véase el dosier dedicado a Demografía y Antropología biológica, Revista de Demografía Histórica, 2001, 19(1).

12 Véase el dosier coordinado por García González y Gasperoni (2019) con artículos de Chacón Jiménez \& Henarejos y Rappo. Otro dosier paralelo sobre Les lois du sang en Annales de démographie historique, 2019/1, $\mathrm{n}^{\circ} 137$, si bien el mundo rural está ausente. También se aborda el tema en varios artículos en Revista de Demografía Histórica, 2019, 37(1), así como Blanco Carrasco (2012b).

13 Cabe destacar en este sentido los proyectos desarrollador desde Girona por Rosa Congost y su equipo como "Dinámicas sociales y cambio histórico en sociedades rurales: el análisis de los grupos y las desigualdades sociales” o “¿Cambio social sin grupos sociales? El seguimiento de trayectorias colectivas en el pasado desde una perspectiva relacional (siglos XIVXX)". Igualment, véase por ejemplo Oris (2008). 
Mundo Agrario, abril-julio 2021, vol. 22, n 49, e159. ISSN 1515-5994

14 Para un ejemplo del potencial de la historia comparada en Ruggiu (2007), si bien es cierto que no es un estudido de corte rural y se refiere al caso de ciudades intermedias. Una reflexión más general en García González, Béaur, Boudjaaba (2016). 